ISSN: 0514-7336 — ISSN electrónico: 2386-3943

DOI: https://doi.org/10.14201/zephyrus202188135161

\title{
AQUAE PLUVIAE ET CADUCAE. SISTEMAS DE DRENAJE E IMPERMEABILIZACIÓN FRENTE A LA ESCORRENTÍA SUPERFICIAL EN AUGUSTA EMERITA (MÉRIDA, ESPAÑA) Y MIROBRIGA (SANTIAGO DO CACÉM, PORTUGAL)
}

\section{Aquae pluviae et caducae. Drainage and Waterproofing Systems to Avoid Surface Runoff in Augusta Emerita (Mérida, Spain) and Mirobriga (Santiago do Cacém, Portugal)}

\author{
Jesús Acero Pérez* y Catarina Felício** \\ *Dpto. de Prehistoria y Arqueología. Facultad de Geografía e Historia. Universidad de Sevilla. Cl Doña María de \\ Padilla, s/n. 41004 Sevilla. Correo-e: jacero@us.es. ID ORCID: https://orcid.org/0000-0003-4265-8399 \\ ** Centro de Humanidades (CHAM). Faculdade de Ciências Sociais e Humanas (FCSH). Universidade Nova de \\ Lisboa. Avda. de Berna, 26 c. 1069-061 Lisboa, Portugal. Correo-e: cfelicio@fcsh.unl.pt. ID ORCID: https://orcid. \\ org/0000-0002-7274-600X
}

Recepción: 24/05/2021; Revisión: 24/07/2021; Aceptación: 19/10/2021

Resumen: Este trabajo se centra en un aspecto apenas tratado en los estudios sobre el urbanismo romano como es el de los sistemas de drenaje del agua circulante por las superficies de tránsito, particularmente en las vías y los espacios públicos. Se presentan como casos de estudio dos ciudades localizadas en la provincia de Lusitania, Augusta Emerita y Mirobriga, exponentes, a su vez, de dos modelos dispares de urbanismo que son aquí confrontados. La primera, la capital provincial, fue una fundación colonial ex novo en la que ya se planificó desde el inicio una red pública de cloacas en correspondencia con el callejero ortogonal. La segunda, Mirobriga, implantada sobre un oppidum prerromano, fue un aglomerado urbano secundario que careció de un verdadero sistema de alcantarillado subterráneo, siendo evacuadas las aguas residuales (tanto las pluviales como las sucias) directamente a través de la superficie de las calles. Si en el primer caso proliferaron los elementos de drenaje para conducir la escorrentía hacia la red de colectores, en el segundo predominó el uso de diferentes estructuras de aislamiento para proteger las fachadas frente al exceso de líquido en superficie.

Palabras clave: Lusitania; urbanismo romano; obras públicas; evacuación hídrica; red de saneamiento; cloacas; aguas pluviales.

АвSTRACT: This work focuses on a hardly analysed issue in Roman urbanism studies, namely the drainage of runoff water from streets and public areas. We present the cases of two cities located in the province of Lusitania, Augusta Emerita and Mirobriga, each one representative of two different urban layouts, which are here compared. The first case, the provincial capital, was a Roman colony founded ex novo which had an underground sewer network designed along with the orthogonal city plan. The second, Mirobriga, developed from a pre-Roman oppidum, was a secondary town that did not have a proper drainage infrastructure, that resulted in both rain and wastewater flowing through the paved streets. While the first case study offered a wide range of drains to carry the runoff to the sewers, the second case produced different waterproofing structures designed to protect the buildings from the excess of water flowing on the surface.

Key words: Lusitania; Roman urbanism; public works; water evacuation; sewage network; sewers; rainwater. 


\section{Introducción ${ }^{1}$}

Se llama escorrentía superficial a la corriente de agua que discurre sobre la superficie de un terreno, sin infiltrarse en el suelo, causada por la precipitación directa o por el derramamiento al rebasar un depósito o un cauce natural o artificial que la contenía. Los asentamientos urbanos, al propiciar el aumento de las superficies impermeables con la instalación de tejados y pavimentos, dificultan la absorción natural de la escorrentía, ocasionando problemas para el tránsito por las calles, que son las principales receptoras de las aguas pluviales. Las ciudades romanas, como las urbes actuales, tuvieron que procurar soluciones frente a la acumulación de agua en las superficies de tránsito, fundamentalmente en las vías y en los complejos públicos con espacios a cielo abierto. Se trata, sin embargo, de un asunto apenas analizado por la investigación arqueológica, más allá del caso excepcional de Pompeya (Koga, 1992; Jansen, 2002: 63-68; Poehler, 2012). En este trabajo planteamos un estudio comparativo de las estrategias de drenaje adoptadas en dos de las ciudades mejor conocidas de la provincia de Lusitania: Augusta Emerita y Mirobriga. Para ello partimos de la documentación arqueológica disponible y de la observación in situ de los restos conservados. La atención se centra en los elementos y estructuras que, a nivel de las superficies de tránsito, tanto en las vías como en los espacios públicos, permitían la evacuación de las aguas de escorrentía y la protección de las fachadas frente a la humedad generada por ellas. Tras la exposición individualizada de los datos relativos a cada ciudad, se presenta una síntesis comparativa que permite considerar las diferencias y semejanzas existentes entre ambos núcleos urbanos.

1 Este trabajo ha sido planificado y realizado en el marco de dos becas de investigación financiadas por la Fundação para a Ciência e a Tecnologia, una de doctorado, adscrita al Centro de Humanidades da Univ. Nova de Lisboa-cham y a la Escuela Española de Historia y Arqueología en Roma-EEHAR-CSIC (DFA/BD/6757/2020), y otra postdoctoral, desarrollada en el Centro de Arqueologia da Univ. de Lisboa-UNIARQ (SFRH/BPD/114887/2016), además de un contrato del Programa Doctores PAIDi 2020, financiado por la Junta de Andalucía y el Fondo Social Europeo y adscrito al Dpto. de Prehistoria y Arqueología de la Univ. de Sevilla.

\section{Augusta Emerita (Mérida, Badajoz)}

\subsection{Contextualización geográfica y urbanistica}

La colonia Augusta Emerita fue una fundación promovida por Augusto entre 25 y 24 a. C., pasando a convertirse apenas una década después en capital de la recién creada provincia de Lusitania. Para su emplazamiento se eligió un terreno libre de construcciones previas y dominado por una alineación de pequeñas colinas situadas en la confluencia de dos ríos: el Guadiana y su afluente el Albarregas (Fig. 1). A pesar del clima cálido y seco, con precipitaciones anuales de apenas 450 a $550 \mathrm{~mm}$ (García Marín y Mateos, 2010), el lugar se caracteriza por la abundancia de agua, tanto en el propio solar urbano como en sus cercanías. De hecho, cuatro acueductos, construidos a lo largo del s. I d. C., aseguraron el abastecimiento hídrico (Pizzo, 2015), al margen de las reservas con las que contaba la mayoría de $d o-$ mus, bien a través de pozos que captaban del manto freático, bien a través de cisternas que almacenaban el agua de lluvia (Alba, 2001a).

El perímetro amurallado, con una superficie aproximada de 70 ha, adquirió una planta irregular por la adaptación de la cerca defensiva a la orografía. No obstante, en su interior se estableció un callejero de diseño ortogonal, con espaciosas vías en damero (Mateos, 2011), pavimentadas con sólidos enlosados pétreos y provistas de pórticos laterales (Alba, 2001b, 2002). Para permitir la evacuación de las aguas residuales se concibió ya en el proyecto fundacional un sistema público de cloacas, también de trazado reticular, en correspondencia con el viario urbano, aunque el proceso de instalación demoró varias décadas hasta completar toda la superficie urbana. Esta red está integrada por grandes galerías abovedadas construidas en opus incertum, con unas dimensiones internas que oscilan, salvo excepciones, entre los 0,50 y $0,85 \mathrm{~m}$ de anchura y entre 1,15 y $1,50 \mathrm{~m}$ de altura ${ }^{2}$. Las pendientes de estos colectores se adaptaban al relieve, encauzando las aguas residuales hacia el Guadiana. En el espacio extramuros, por su parte, a lo largo del s. I d. C. surgieron nuevos barrios que sobrepasaron los límites urbanos iniciales, con una ordenación urbanística

2 Para una descripción pormenorizada de las cloacas emeritenses, que no son objeto de estudio específico en este trabajo, véase Acero (2018: 140-181).

Ediciones Universidad de Salamanca / 요요 
J. Acero Pérez y C. Felício / Aquae pluviae et caducae. Sistemas de drenaje e impermeabilización

frente a la escorrentía superficial en Augusta Emerita (Mérida) y Mirobriga (Santiago do Cacém, Portugal)

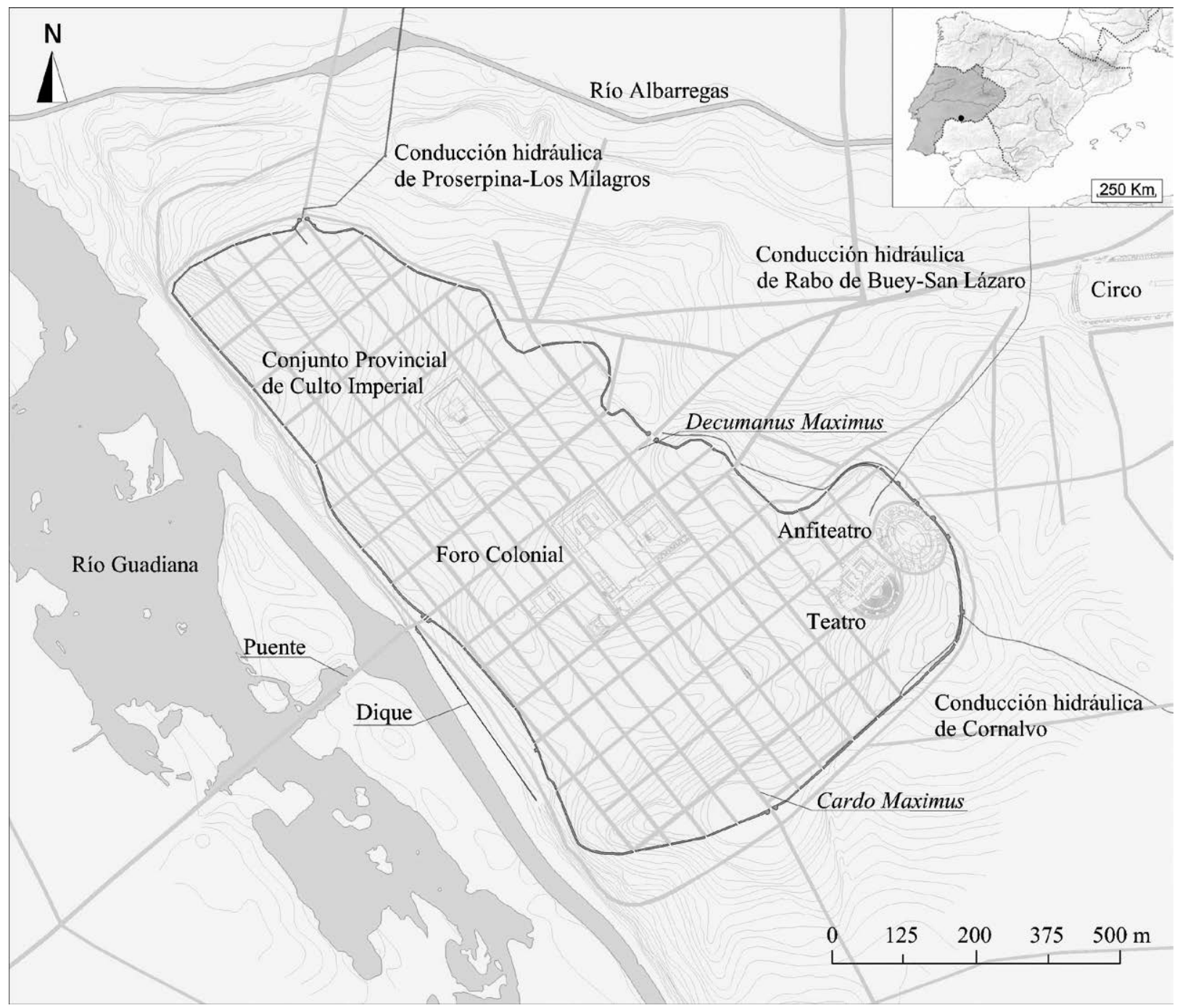

Fig. 1. Plano de Augusta Emerita (a partir de la base cartográfica del Consorcio de Mérida; mapa de localización adaptado de Ancient World Mapping Center, disponible en https://awmc.unc.edu/wordpress/).

más arbitraria, aunque no exenta de cierta planificación ni tampoco de un servicio de cloacas que, en esta zona, sobre todo en la franja noroeste, se encaminaba hacia el río Albarregas.

\subsection{Sistemas de drenaje}

\subsubsection{Vías}

En una fase inicial las calles emeritenses parecen haber funcionado provisionalmente con superficies de tierra y sin cloaca (Alba, 2001b: 403), hasta que se completó en todo el recinto intramuros la construcción de los enlosados pétreos, junto con la instalación del servicio público de alcantarillado y la edificación de los pórticos laterales, un proceso que parece extenderse en el tiempo hasta alcanzar, en algunos casos, la segunda mitad del s. I d. C. (Acero, 2018: 171-176). En el empedrado de las vías, con una anchura que oscila, por término medio, entre los 5 y $6 \mathrm{~m}$, se emplean grandes losas irregulares de diorita, anfibolita y cuarcita, mostrando un característico aspecto multicolor en el que se combinan los 
tonos azulados, grises y rosáceos. No faltan excepciones a esta pauta generalizada, destacando el cardo maximus, que parece haber recibido un tratamiento diferencial, reflejado tanto en la anchura de su calzada, que llega a los $9 \mathrm{~m}$ (Mateos, 2011: 132), como en su recorrido, jalonado por estructuras de carácter público entre las que se incluye el foro colonial, zona en la que esta vía se presenta sin pórticos -por la propia monumentalización de la fachada de este recinto- y con una pavimentación granítica en lugar del enlosado habitual (Ayerbe et al., 2009: 717 718). Salvo en esta y otras vías que presentan ciertas particularidades, como las que rodean los graderíos del teatro y del anfiteatro, un elemento distintivo de las calles altoimperiales emeritenses es la generalización de pórticos laterales, de entre 2,5 y $3 \mathrm{~m}$ de anchura, sostenidos en columnas de granito (Alba, 2002: 375). Estas margines peatonales estuvieron provistas de pisos de tierra de composición variable o de opus signinum y se encontraban protegidas inicialmente por bordillos de granito, manteniendo una cota ligeramente superior a la del pavimento de la calzada, lo que evitaba la entrada del agua de escorrentía. De hecho, las calzadas suelen presentar un perfil convexo, propiciando el encauzamiento del agua de lluvia hacia los laterales (Alba, 2001b: 404), donde era drenada a través de imbornales habilitados a tal efecto, desde los que partían canales conectados con la cloaca central. Acciones posteriores de recrecimiento y repavimentación de las vías tendieron a aplanar su sección, facilitando la circulación del tráfico rodado, pero en detrimento de las condiciones de drenaje.

Es un detalle significativo, en cuanto a los imbornales, que algunos de ellos se localicen junto a los soportes graníticos de los pórticos laterales (Fig. 2), lo que parece revelar que también se encargaban de evacuar las aguas llovedizas procedentes del tejado de los soportales (Acero, 2018: 181). Hay que suponer, así pues, la existencia de canalones en los aleros de los tejados, desde los que partirían tuberías bajantes adosadas a las columnas de los pórticos, hasta alcanzar los imbornales a pie de calzada.

Hasta el momento conocemos dos tipos de imbornales, es decir, las aberturas a través de las cuales

Ediciones Universidad de Salamanca / 요 el agua pasaba a los canales bajo el pavimento viario. El primero estaría conformado por una tapa, que podría ser una rejilla metálica o una loseta de piedra calada, situada en el extremo inicial del canal de evacuación, apoyando sobre sus paredes. Aunque no se ha conservado ninguna, su presencia puede inferirse por el hueco existente en el arranque del canal y, en algunos casos, por la existencia de un retalle en forma de arco de circunferencia que indica que su planta sería circular (Fig. 3). El segundo tipo corresponde a bloques pétreos perforados, de los que se conservan dos ejemplares de granito aún in situ, ambos situados en las calles adyacentes al teatro. Concretamente, uno de ellos, con un orificio de $28 \mathrm{~cm}$ de diámetro, se encuentra en la vía intermedia entre el anfiteatro y el teatro, junto a la escalinata que descendía hacia la porticus post scaenam. Por su localización es de suponer que contribuía a reducir la escorrentía que por allí descendía durante los días de lluvia, favoreciendo de este modo el tránsito por la escalera. El otro, con una perforación de $19 \mathrm{~cm}$ de diámetro, se sitúa en el lateral del cardo minor que delimitaba este mismo recinto teatral por el lado oeste, en una zona en la que la propia calzada presenta un badén en adaptación a la orografía. Así pues, ayudaría a la evacuación de las aguas pluviales en una zona propensa al encharcamiento ${ }^{3}$.

Otros elementos que ayudaban en el drenaje de las calzadas eran las bocas de registro de las cloacas, aunque no fuera este su cometido principal. Ya fuesen pozos verticales o simples aberturas practicadas en la bóveda de los colectores, se emplazaban tanto en los cruces de cloacas como en otros puntos intermedios de su recorrido (Acero, 2018: 164-167). Su cubierta consistía en uno o varios bloques pétreos que no siempre encontraban un encaje perfecto sobre la abertura, permitiendo así la infiltración del agua al interior de los conductos. En el caso concreto de la boca de registro localizada en el

3 Aunque existían sospechas de tratarse de una pieza reutilizada (Acero, 2018: 183, n. 236), recientes intervenciones en la zona han confirmado la función de este imbornal (Consorcio de Mérida, n. ${ }^{\circ}$ de interv. 8515), que ya había sido definido como un 'traga-aguas' por su descubridor (Floriano, 1944: 173). 

frente a la escorrentía superficial en Augusta Emerita (Mérida) y Mirobriga (Santiago do Cacém, Portugal)



FIG. 2. Canales viarios que parten desde los soportes del pórtico de un cardo minor; en el centro otro canal procede del inmueble aledaño en la actual cl Almendralejo, 11, de Mérida (P. Delgado, Consorcio de Mérida).

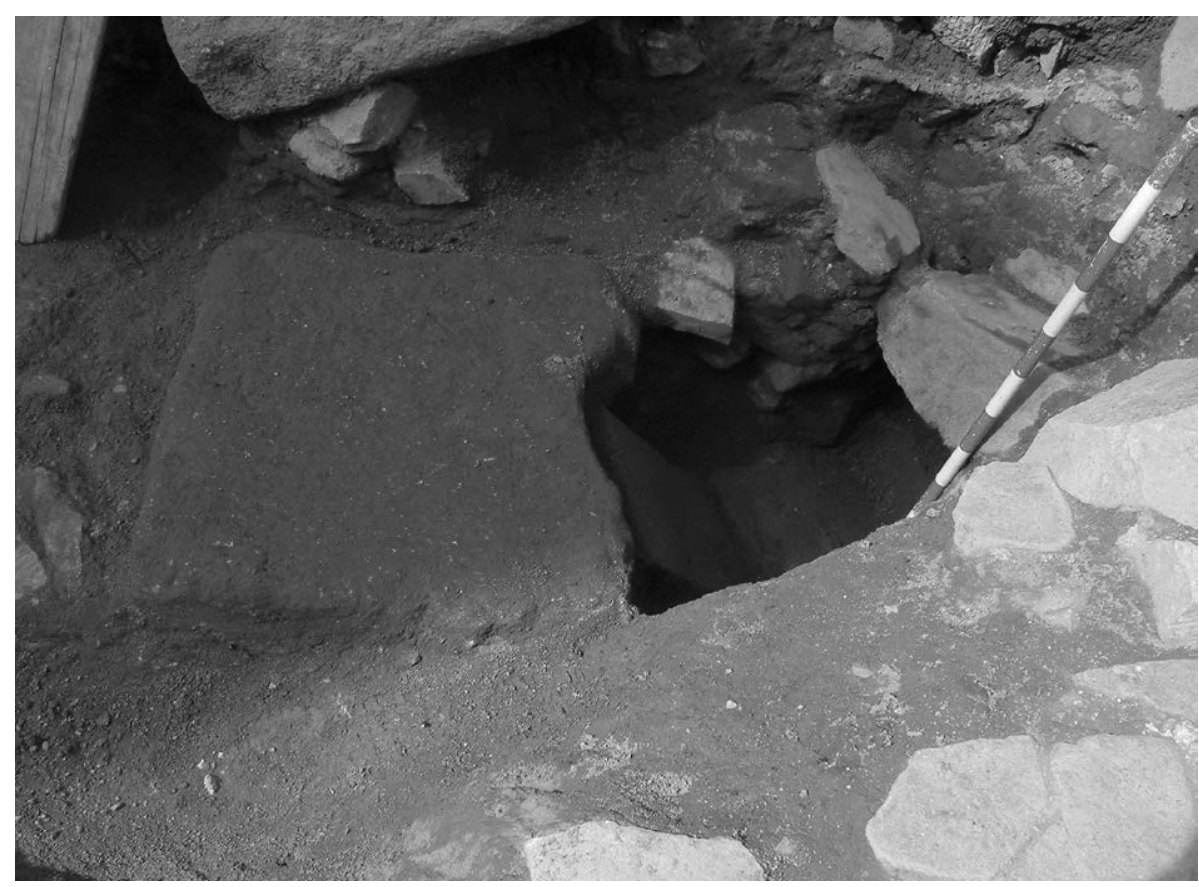

Fig. 3. Soporte del pórtico de un cardo minor retallado para permitir el encaje de la tapa de un imbornal en la actual c/ Pizarro, 2, de Mérida. decumanus de la actual cl Viñeros, la pieza granítica que servía de tapadera no cubría el hueco completo (Palma, 2009: 363), dejando una 'ranura' de aproximadamente $30 \mathrm{x}$ $57 \mathrm{~cm}$ por donde entraba el líquido, a no ser que en origen también esta parte se encontrase taponada por otras piezas pétreas menores no conservadas (Fig. 4).

En las calles extramuros no se conocen, hasta el momento, ni pozos de registro ni imbornales viarios. Esto no quiere decir que tales elementos no existieran, por lo menos los primeros, indispensables para el correcto mantenimiento del alcantarillado, aunque probablemente no resultaban tan frecuentes como en el núcleo urbano. Fuera del encintado urbano las cloacas se fueron añadiendo progresivamente para dar servicio a los nuevos suburbia, pero creando una red de saneamiento menos tupida y ordenada que en el interior del recinto amurallado (Acero, 2018: 141-142). De hecho, importantes viales extramuros, sobre todo aquellos que recorrían áreas de uso preferentemente funerario, con escasa presencia de estructuras domésticas, 
no llegaron nunca a disponer de cloacas. Las pavimentaciones también difieren respecto al espacio intra moenia, pues, aunque existen los enlosados pétreos, especialmente en los tramos más próximos al recinto urbano, predominan los encachados a base de pequeños guijarros, gravas y tierra compactada (Sánchez Barrero, 2010: 71-78). Tampoco se han

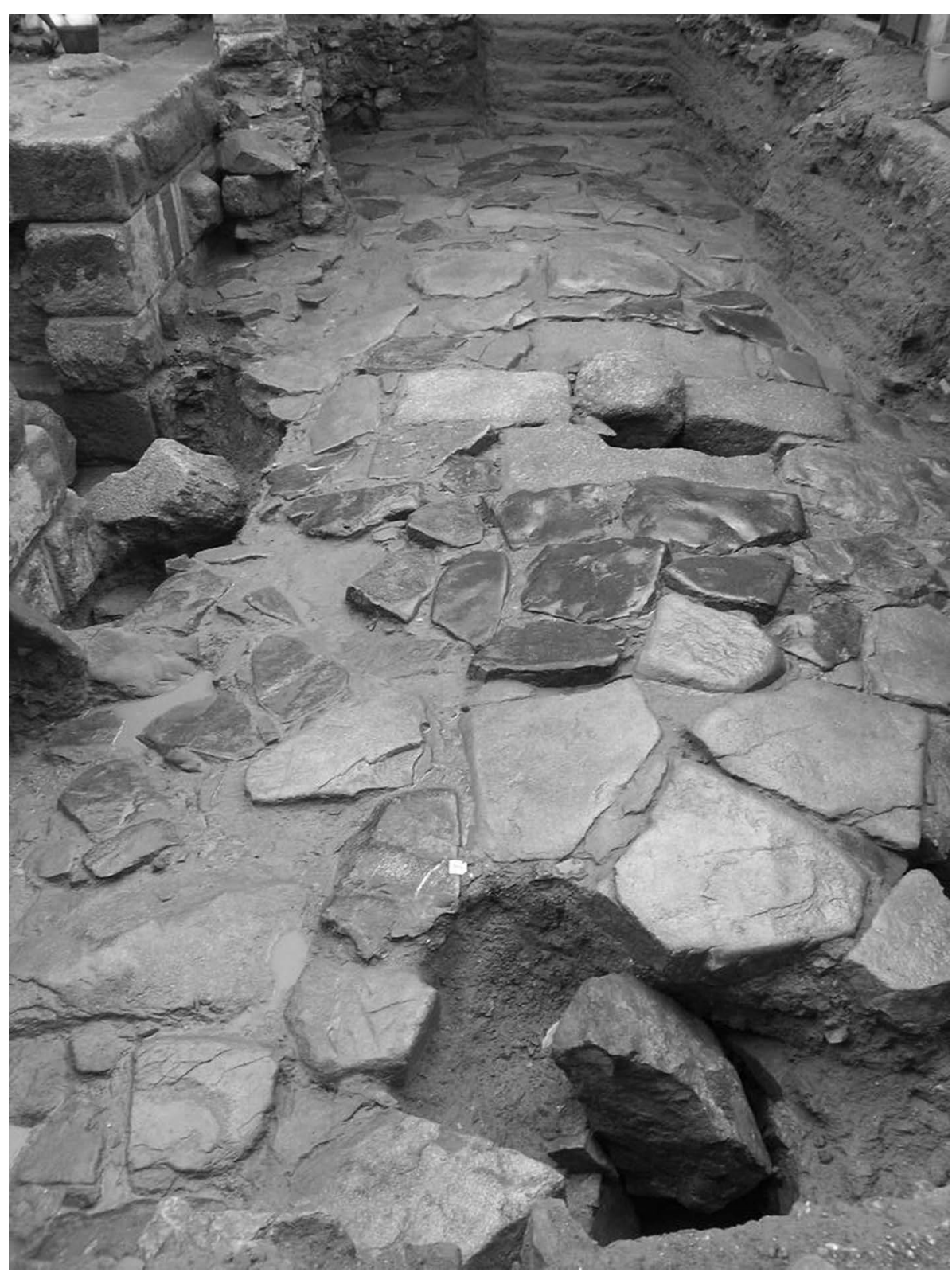

Fig. 4. Boca de registro en el decumanus minor localizado junto al templo de la actual cl Viñeros, 3, de Mérida (F. Palma, Consorcio de Mérida). detectado pórticos, a excepción de la vía que comunicaba el anfiteatro con el circo, monumentalizada entre los ss. II y III d. C. con la incorporación de este espacio en al menos una de sus margines (Ayerbe y Márquez, 1998).

La ausencia de colector subterráneo obliga a una evacuación de la escorrentía a través de la propia superficie de las vías, dirigiendo el flujo hacia los laterales gracias al perfil ligeramente convexo que también suelen presentar las calles o caminos extramuros. El agua acabaría por infiltrarse en el terreno, favorecida por la composición permeable de los sucesivos estratos que integran estos ejes viarios. Únicamente en dos casos han sido localizados canales laterales en paralelo a la calzada, uno en la zona norte (Barrientos, 2006) y otro al oeste, en la mencionada vía porticada (Ayerbe y Márquez, 1998), encargándose ambos, suponemos, de encauzar las aguas llovedizas hacia determinados puntos de desagüe. Otro medio de encauzamiento más simple era la existencia de una somera zanja o cuneta lateral, de la que se conoce un solo ejemplar, con revestimiento impermeabilizante, localizado en el tramo de vía visible junto a la Casa del Mitreo (Sánchez Barrero, 2010: 73, fig. 39). Aquí la calzada sí estaba dotada de cloaca, aunque los restos conservados no 
permiten definir si habría conexión entre ambas estructuras ${ }^{4}$.

Asimismo, para minimizar la entrada de agua en las calzadas extramuros desde los terrenos adyacentes se emplearon, a veces, otros dos recursos constructivos, aplicados o no en simultáneo: la elevación de la vía sobre un terraplén y la erección de muros laterales que se alzaban ligeramente sobre la rasante. Ejemplos de terraplenes o elevación de calzadas son aún perceptibles en la denominada 'Vía de la Plata', a su paso por las inmediaciones del actual

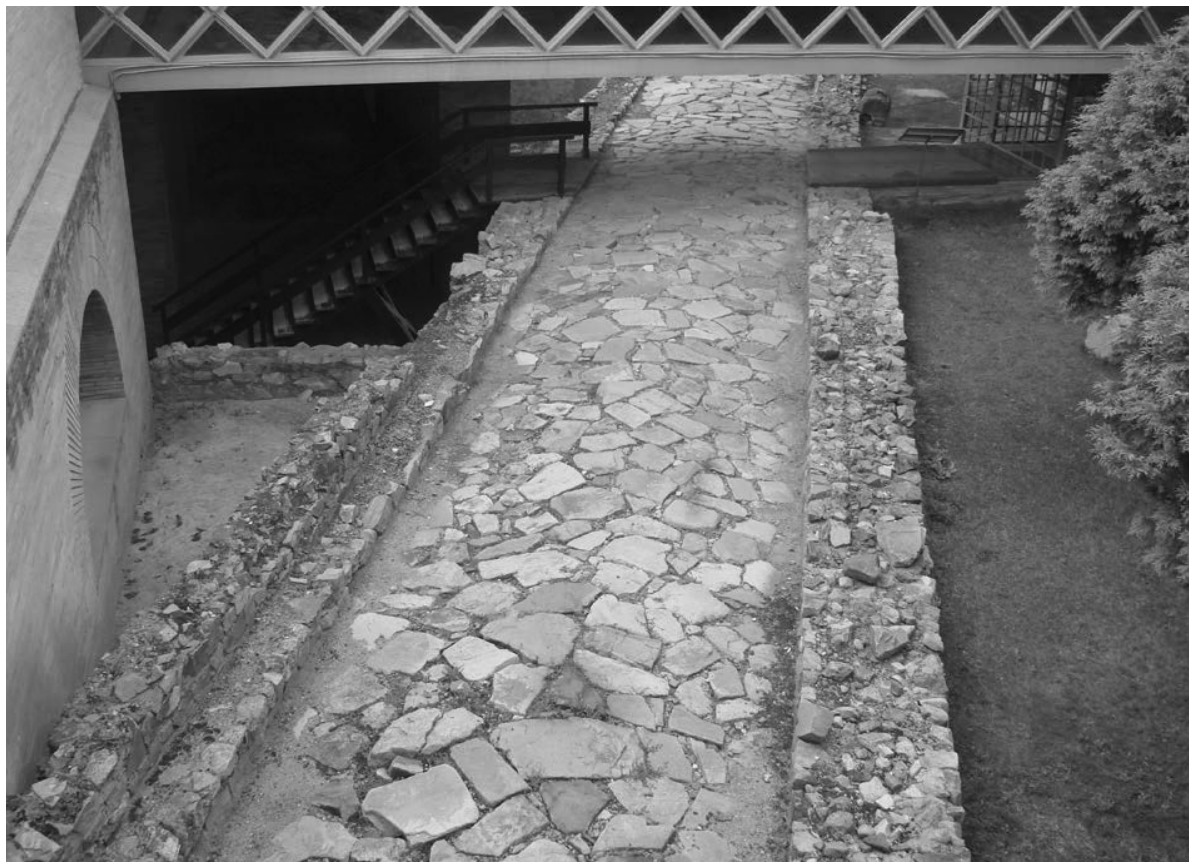

Fig. 5. Aterrazamiento y muros laterales en la calzada extramuros conservada en el Museo Nacional de Arte Romano de Mérida.
(Sánchez Barrero, 2010: 113, fig. 78), o en la calzada conservada en la cripta del Museo Nacional de Arte Romano, en este caso delimitada por muros laterales (Fig. 5). Otros ejemplos de vías con muros corridos en las márgenes, pero sin terraplén, o con una elevación muy somera, han sido documentados en el solar del antiguo cuartel Hernán Cortés (Sánchez Hidalgo et al., 2019) y en la barriada de Plantonal de la Vera (Sánchez Hidalgo, 2017). Estos muros en las márgenes, cuando existía terraplén, también desempeñaban un papel esencial en la contención de las tierras que lo componían 5 .

Por otro lado, hay que considerar los efectos que tuvieron en el drenaje los cambios que afectaron a la fisonomía del callejero a lo largo del tiempo, sobre

4 Recientemente se ha identificado lo que parece tratarse de otra zanja lateral, también con mortero hidráulico, en una vía intramuros documentada en la c/ Muza, aunque el estado de conservación es deficitario (Sánchez Hidalgo, 2019: 219).

5 No se deben confundir estos muros con las simples fajas o cintas de piedra que con frecuencia aparecen delimitando los bordes de las calzadas. todo en el espacio intramuros. En este sentido, cabe referirse, en primer lugar, a la privatización de los pórticos peatonales, un fenómeno largamente constatado en el Occidente romano (Ruiz Bueno, 2018: 37-52) y que en Augusta Emerita parece iniciarse en el s. II d. C., intensificándose a lo largo de los ss. III y IV con el desarrollo arquitectónico que experimentan las domus y el crecimiento de estas a costa del espacio público (Alba, 2002: 379-380). Este proceso de apropiación supuso la construcción de nuevas fachadas adelantadas hasta el límite de las calzadas y, en ocasiones, incluso sobrepasándolo. Así, estas paredes quedaron expuestas al contacto directo con la escorrentía y a los consecuentes problemas de humedad. De ahí que hayan sido documentados al menos dos casos en los que se impermeabilizó la zona de contacto entre el paramento y la calzada, bien anteponiendo a la fachada un 'refuerzo' de piedras y otros materiales reutilizados muy fragmentados (Palma, 2001: 231), bien aplicando un revoco de opus signinum ligeramente inclinado, como se conserva en la fachada norte de la denominada Casa de los Mármoles (vid. infra Fig. 20c). 
Otro elemento de transformación fue la ocultación de los primitivos enlosados pétreos bajo nuevos pisos de tierra, fenómeno también extendido ampliamente en las ciudades hispanas (Ruiz Bueno, 2018: 37-52) y que, en el caso emeritense, se generaliza desde el s. IV en adelante (Alba, 2001b: 407-410). Este cambio en las superficies de tránsito debió disminuir la capacidad drenante de las vías, por tres motivos fundamentalmente. En primer lugar, la primitiva sección convexa de las vías fue sustituida por superficies horizontales, favoreciendo la acumulación del agua y el consiguiente encharcamiento del espacio de tránsito. En segundo lugar, el efecto del agua fomentaba la erosión de los pisos de tierra, acelerando de este modo el proceso de colmatación de las propias cloacas al infiltrarse los sedimentos a través de los imbornales viarios. Por último, los mismos imbornales terminaron siendo taponados e inutilizados ante los sucesivos recrecidos de los pavimentos terrizos.

\subsubsection{Edificios públicos}

La evacuación de la escorrentía superficial fue un aspecto también planificado en los grandes edificios públicos, variando el sistema en función de la propia configuración de cada recinto. En el caso de las grandes plazas, estas constituyen espacios a cielo abierto con una extensa superficie a drenar, a menudo rodeada por pórticos. En tres de estos recintos -el conjunto provincial de culto imperial, el recinto sacro oriental del foro colonial y la porticus post scaenam del teatro- se conocen grandes canales perimetrales situados a los pies de las columnatas para recoger las aguas vertidas desde las techumbres (Fig. 6A-C). A esta finalidad meramente funcional se une, además, otra ornamental, según se desprende de las dimensiones holgadas de los canales y del hecho de que estos se encontrasen a cielo abierto, sin cubierta. Esto exigía una presencia de agua constante, solo asegurada a través de un sistema de provisión ligado al servicio público de abastecimiento. Así parece constatarse en la porticus post scaenam del teatro, donde se conserva una tubería de abastecimiento que aprovechaba, probablemente, el agua sobrante de una fuente situada junto a uno de los extremos del canal (Ayerbe, 2019: 111-112). En la gran plaza central del foro colonial, por el contrario, el canal perimetral discurría oculto bajo
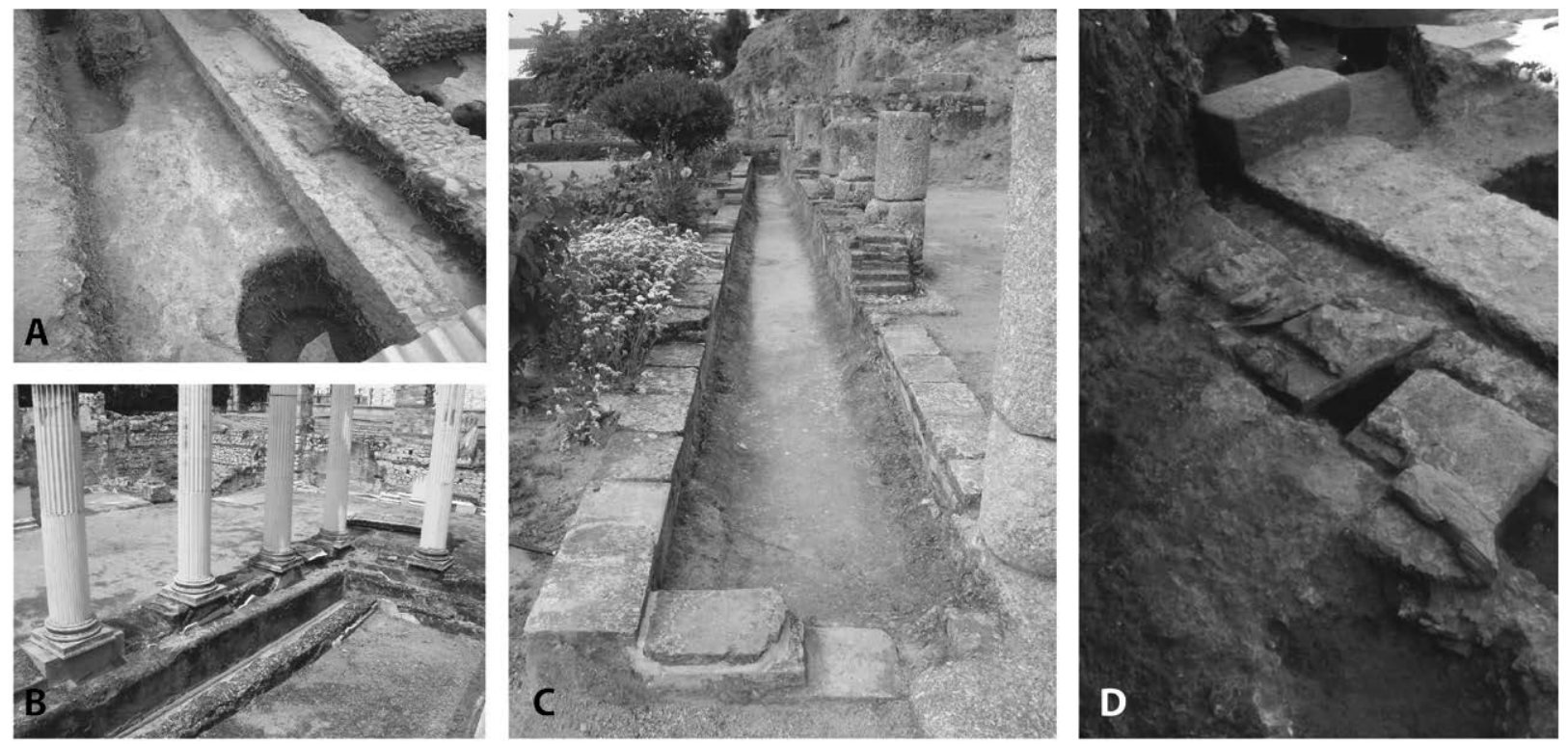

FIG. 6. Canales perimetrales en los recintos porticados emeritenses: A) Conjunto provincial de culto imperial (Mateos, 2006: fig. 87); B) Recinto sacro oriental del foro colonial; C) Porticus post scaenam del teatro; D) Plaza central del foro colonial (R. Ayerbe, Consorcio de Mérida). 
los escalones que existían entre el espacio central y los edificios porticados, por lo que solo se le puede atribuir una función de evacuación, lejos de cualquier pretensión decorativa (Fig. 6D). En este caso cabe suponer, como así hacen sus descubridores (Ayerbe et al., 2009: 706, n. 178), que el agua llegaría a su interior a través de sumideros colocados a lo largo de su trazado, recogiendo tanto la escorrentía superficial como las pluviales de las techumbres del pórtico, a través de bajantes conectadas con dichos sumideros.

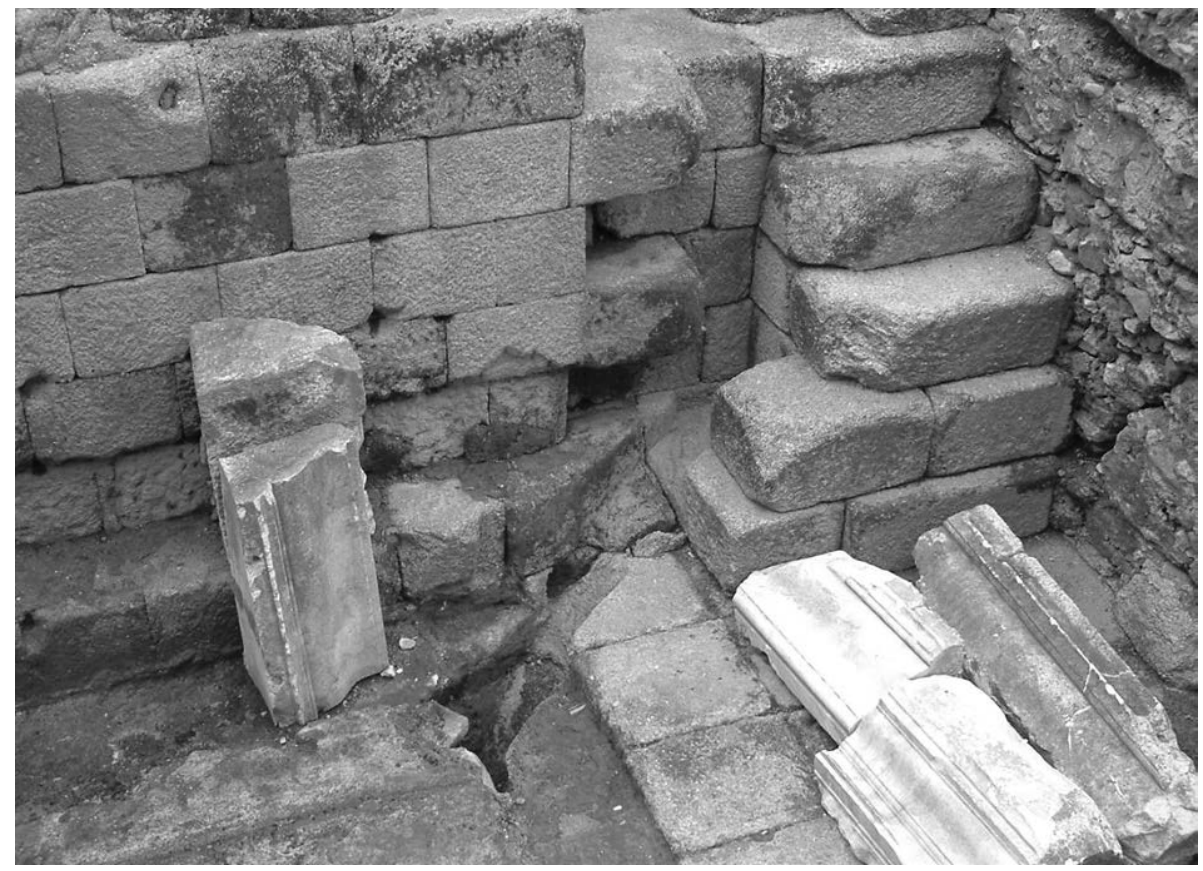

Fig. 7. Bajante en el templo del conjunto provincial de culto imperial en la actual cl Holguín, 37 de Mérida (Mateos y Pizzo, 2006: fig. 130).
En los otros recintos mencionados, en cambio, los canales perimetrales solo evacuaban el agua de lluvia procedente de las techumbres, no la circulante por la superficie del área abierta, puesto que se interponían las propias paredes que conformaban la canalización, situadas a una cota mayor respecto al pavimento de la plaza. En estos casos la escorrentía sería recogida a través de sumideros colocados en ciertos puntos de la explanada hacia los que se dirigía la pendiente, conectados, a su vez, con canales subterráneos de evacuación. Uno de ellos fue documentado en el conjunto provincial de culto imperial, concretamente en el ángulo noroeste de la plaza (Mateos, 2006: 102 y 114).

Por otra parte, el templo que presidía este último recinto, caracterizado por su peculiar planta de cella barlonga, dispuesta de forma transversal al pronaos, exigió habilitar bajantes en los dos ángulos que se formaban entre ambos espacios, donde confluían las vertientes de ambas cubiertas. Se ha conservado, al menos, la situada en el lado este (Mateos y Pizzo, 2006: 130), en forma de caja o hueco vertical de planta casi cuadrangular de $45 \mathrm{x}$

Ediciones Universidad de Salamanca / @®্ত
$49 \mathrm{~cm}$, ejecutada entre los sillares que conformaban la pared del podium (Fig. 7). Parece probable que en su interior se alojase una tubería, hoy perdida, que tenía continuidad a través de una canalización de desagüe conservada bajo el pavimento de la plaza.

En cuanto a los edificios de espectáculos, su configuración arquitectónica los convertía en grandes cuencas artificiales de deposición, en las que el agua tendía a acumularse en las zonas bajas. Así, en el anfiteatro toda la escorrentía confluía en la fossa arenaria, donde se habilitó una cloaca que salía bajo el gran vomitorio occidental del edificio, prolongándose por la porticus post scaenam del vecino teatro. Por su parte, en el edificio teatral toda el agua, tanto la llovediza que caía por el graderío como la que se derramaba desde las fuentes que muy probablemente decoraban el proscaenium, se concentraba delante de este muro. Allí el líquido pasaba, a través de varios sumideros de formato y dimensiones dispares, al interior de una cloaca que discurría en paralelo al proscaenium y que salía por el aditus occidental para conectar, previsiblemente, con la procedente del anfiteatro (Fig. 8). En torno a estos dos colectores se 

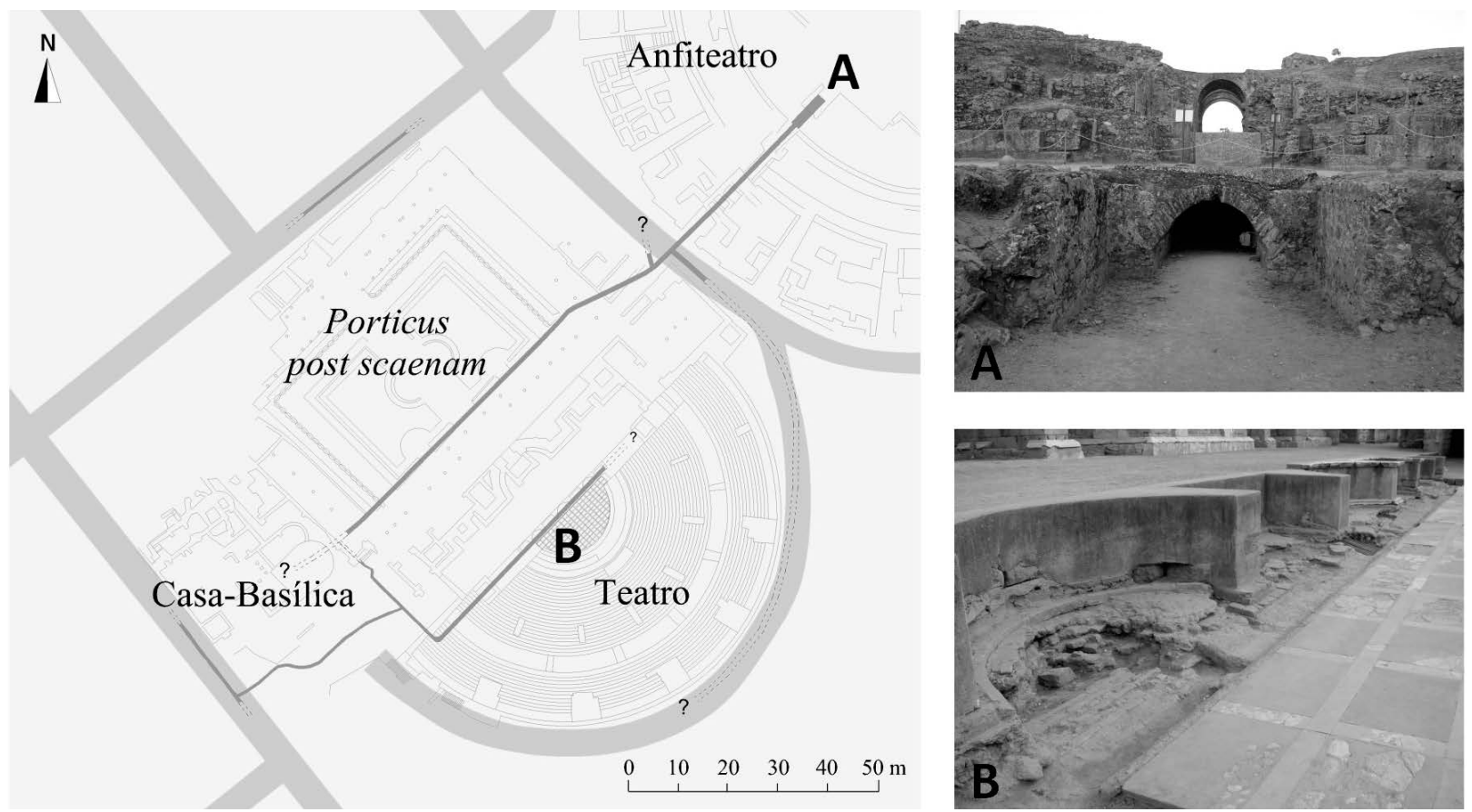

Fig. 8. Red de saneamiento en torno al teatro y al anfiteatro emeritenses: A) Inicio de la cloaca en la fossa arenaria; B) Extradós de la cloaca en el proscaenium.

articuló, además, un entramado de cloacas que completaron el desagüe de este conjunto monumental, entre las que cabe destacar la situada bajo la vía perimetral del hemiciclo del teatro y la que, partiendo de la versura occidental del teatro, conectaba el colector procedente de la orchestra con la situada bajo el cardo minor situado inmediatamente al oeste.

También hubo preocupación por mantener libres de agua las principales zonas de paso en ambos edificios, aunque aplicando soluciones muy sencillas. Así, en las praecinctiones del anfiteatro una serie de sumideros y pequeños canales de desagüe colocados a intervalos regulares evitaban la acumulación de agua en los corredores, pero desviando el líquido hacia el graderío, por donde se deslizaba libremente, en superficie, hasta alcanzar la arena (Fig. 9). Un sistema semejante, a través de pequeńos orificios de desagüe, se habilitó en el teatro para evitar el encharcamiento en los seis pequeños corredores radiales que conectaban la crypta interior con la ima cavea. Asimismo, una reforma afectó a los vomitorios de la fachada semicircular del teatro cuando, probablemente en época bajoimperial, la calle fue recrecida (Alba, 2001b: 404 y 406), quedando a mayor altura que los propios umbrales, por lo que hubo que habilitar en las entradas, según los casos, uno o dos peldaños de granito. Para evitar el encharcamiento, particularmente en aquellos vomitoria con escaleras para acceso a la media y summa cavea, en los que se creaba un rellano, se protegió el suelo con un grueso pavimento de opus signinum y fueron ejecutadas unas canaletas excavadas en los umbrales (Fig. 10). Dichas canaletas parecen tener continuidad, ya en forma de canales de fábrica, bajo la vía circundante, hasta desembocar en la cloaca allí existente. Para minimizar la entrada de agua en los vomitorios desde la calle, esta fue provista de un perfil ligeramente cóncavo, con una leve depresión en su eje, siendo el único caso con esta sección documentado hasta ahora en Mérida ${ }^{6}$.

6 Está pendiente de confirmar si, como se ha propuesto, las rejillas de desagüe que en la actualidad pueden verse repartidas por el eje de esta vía están reutilizando pozos de registro o imbornales originales de época romana conectados con la cloaca subyacente (Acero, 2018: 188). 

frente a la escorrentía superficial en Augusta Emerita (Mérida) y Mirobriga (Santiago do Cacém, Portugal)

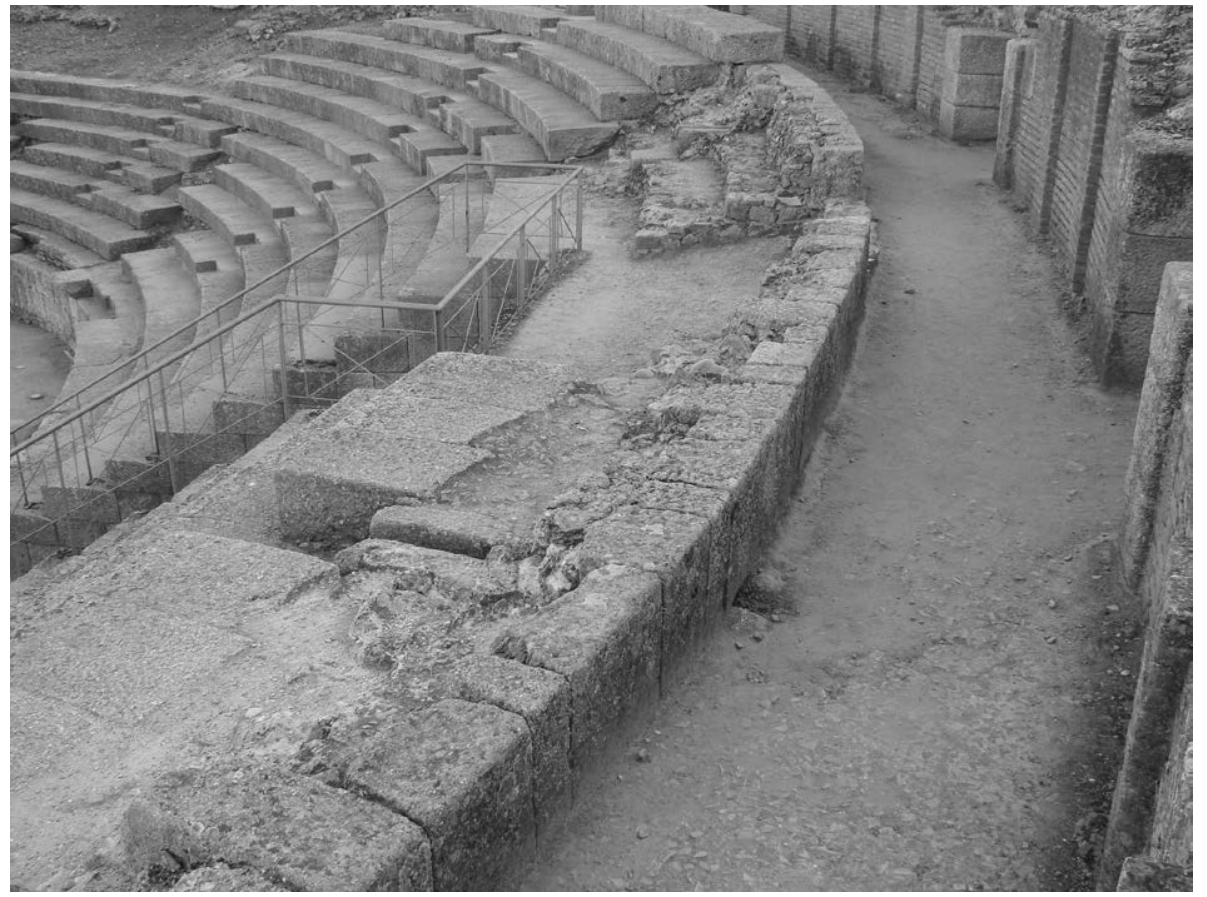

FIG. 9. Sumidero y canal en la praecinctio entre la ima y la media cavea del anfiteatro emeritense.

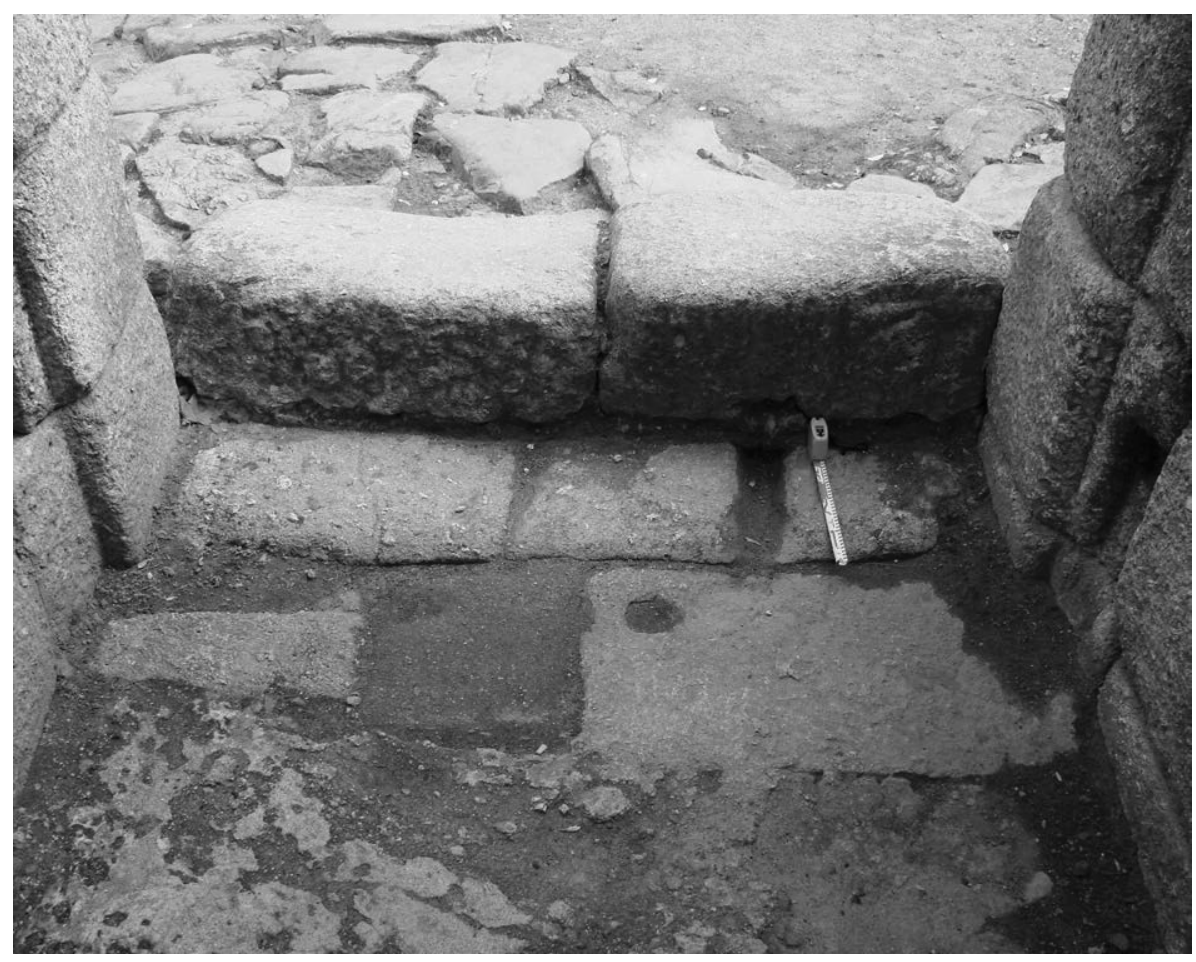

FIG. 10. Canaleta en el rellano de uno de los vomitoria de acceso al teatro emeritense.
Por último, el circo, el mayor de los edificios de espectáculos, fue levantado en una posición extramuros, al noreste de la población, en una zona con declive hacia el cercano río Albarregas. De hecho, su construcción parece haber interrumpido una pequeña vaguada que hubo que canalizar a través de un conducto que cruza perpendicularmente el edificio de norte a sur, pasando junto al extremo occidental de la spina (Fig. 11). Aunque inicialmente fue considerado como un canal de drenaje de la arena (Mélida y Macías, 1929: 7), la ausencia de sumideros en su cubierta invalidaría tal interpretación, a lo que se suma el hecho de atravesar todo el edificio, evidenciando que su función primordial era canalizar una corriente de agua proveniente del exterior, tal como han planteado las últimas investigaciones sobre el edificio (Montalvo et al., 1997: 251; Gijón y Montalvo, 2011: 199). No obstante, el conducto también acabó por cumplir una función como colector, puesto que en una fase posterior se le conectó, rompiendo su fábrica, el canal de evacuación del euripus occidental. Otro 


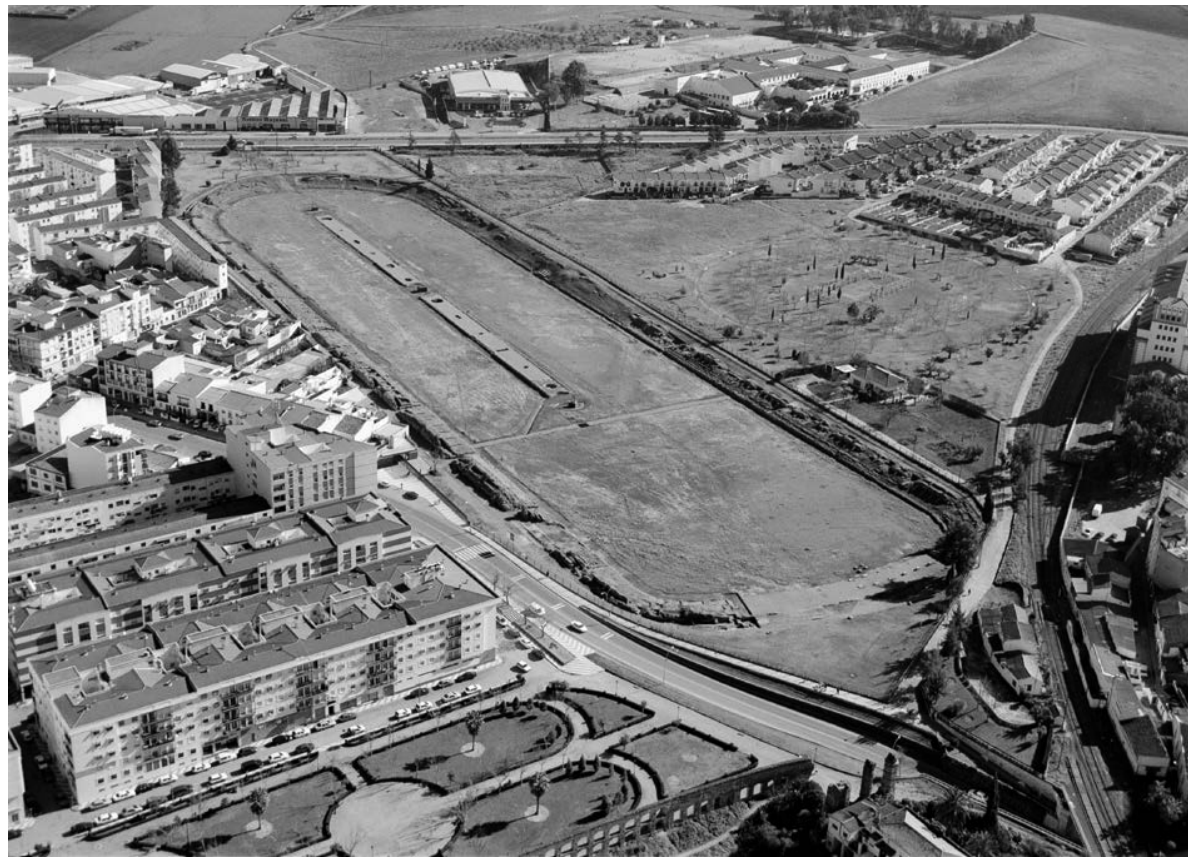

Fig. 11. Vista aérea del circo de Mérida desde el NO, en la que se observa el trazado del canal que cruza perpendicularmente la arena y del desagüe del euripus occidental (Consorcio de Mérida).

conducto en el extremo opuesto de la spina permitía el desagüe del euripus oriental, aunque en este caso el corto tramo documentado impide conocer su destino final (Montalvo et al., 1997: 250). Al margen de estas canalizaciones no parece que existiera en la arena una infraestructura orientada específicamente al drenaje de la pista. En este sentido, la escorrentía superficial fluiría libremente, favorecida en su movimiento por la pendiente natural orientada hacia el lado norte, desde donde alcanzaría el exterior del edificio saliendo directamente a través de los vomitorios, todos ellos abiertos en este flanco al mismo nivel de la arena.

\section{Mirobriga (Santiago do Cacém, Portugal)}

\subsection{Contextualización geográfica y urbanistica}

También conocido como 'Herdade dos Chãos Salgados' o 'Castelo Velho', el sitio arqueológico de Mirobriga se extiende por un conjunto de pequeñas colinas que forman parte de la cadena de sierras de Grândola y Cercal, situándose este enclave apenas a un kilómetro del núcleo urbano de Santiago do Cacém y a unos 15 $\mathrm{km}$ de la costa atlántica y de la actual Sines. Su proximidad litoral le confiere un clima templado, aunque apenas cuente con una precipitación media anual de $549,7 \mathrm{~mm}^{7}$.

Por su localización y dimensión este lugar ha sido tradicionalmente asociado, desde el s. XVI, con la ciudad de MirobrigalMirobrica referida por Plinio (Hist. Nat. 4. 116 y 118) y Ptolomeo (Geog. 2. 4), si bien esta identificación no es del todo segura, pues los hallazgos epigráficos aún no han proporcionado un topónimo claro (Encarnação, 1996). Con todo, a pesar de la discusión en torno a su nombre, no hay dudas respecto a su carácter urbano, tal como la investigación viene poniendo de manifiesto en las últimas décadas (Biers, 1988; Barata, 1998; Quaresma, 2012; Teichner, 2018a).

Aunque los límites del área urbana todavía no están definidos, hasta el punto de que aún no se conocen restos de muralla, el estado actual de conocimiento permite caracterizar la morfología y la dinámica urbanística de este enclave. La población tuvo su origen en los ss. IX-VIII a. C. a juzgar por los materiales documentados, si bien las estructuras más antiguas conocidas datan de los ss. V-IV a. C. (Slane et al., 1983: 54-56). Se trata, por tanto, de un oppidum de la Edad de Hierro que pasó a

Datos correspondientes a 1971-2000. Fuente: IPMA-Estação de Alvalade do Sado (https://www.ipma.pt/bin/ file.data/climate-normal/cn_71-00_ALVALADE.pdf; acceso: 18/03/2021). 
frente a la escorrentía superficial en Augusta Emerita (Mérida) y Mirobriga (Santiago do Cacém, Portugal)

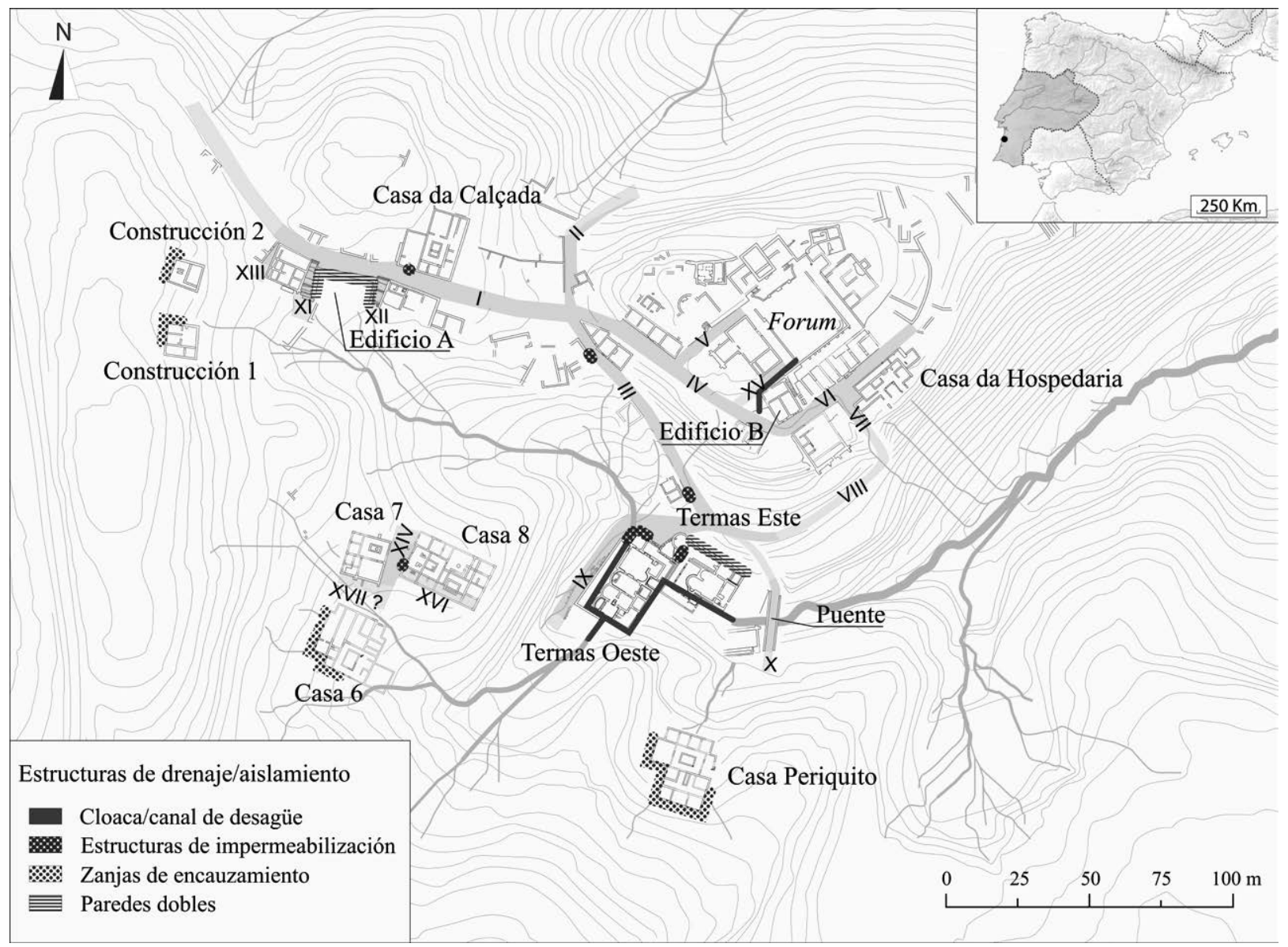

Fig. 12. Plano de Mirobriga (a partir de la base cartográfica de Mirobriga, con adición de las líneas de flow accumulation presentadas en Teichner, 2018b: fig. 4; mapa de localización adaptado de Ancient World Mapping Center, disponible en https://awmc.unc.edu/wordpress/).

convertirse en una civitas romana. La presencia de cerámica itálica se da ya desde el s. II a. C., aunque esta primera conexión económica no parece haber tenido un gran impacto, que solo se manifiesta intensamente a partir de mediados del s. I d. C. (Quaresma, 2012: 28-30), justamente cuando se inició la transformación urbana del poblado. La construcción del complejo del foro, con un terminus post quem del 60 d. C. (Biers et al., 1982; Teichner, 2018d), necesitó de un importante terraplenado que parece haber destruido la casi totalidad de las edificaciones existentes en la colina donde se asienta, momento que representa el corte definitivo con el urbanismo precedente. En esta fase la ciudad también se expande hacia las otras colinas de su entorno. De hecho, los edificios privados conocidos se datan genéricamente en época flavia (Quaresma, 2012: 54; Teichner, 2018a $)^{8}$, coincidiendo con este momento de conversión del asentamiento en una ciudad a la romana.

En cualquier caso, Mirobriga presenta un urbanismo disperso, caracterizado por la presencia de distintos núcleos conectados por vías, no siguiendo la ortogonalidad típica de las ciudades romanas (Fig. 12). Tanto el trazado viario como la parcelación se

8 También vid. Sousa, F.: A Casa da Calçada, Mirobriga. Diacronia de um Edifício Habitacional de Época Romana (séculos I a IV d.C.). Dissertação de Mestrado em Arqueologia presentada en 2019 en la Faculdade de Ciências Sociais e Humanas da Univ. Nova de Lisboa, p. 63. 
vieron condicionados por la orografía, adquiriendo una configuración desagregada (Barata, 1998: 79-80 y 94). Varios de sus edificios se implantaron en zonas de pendiente, encontrándose construidos contra el terreno y parcialmente enterrados, lo que afectó a los sistemas de evacuación hídrica como a continuación veremos.

\subsection{Sistemas de drenaje}

\subsubsection{Vías}

Es posible que algunas de las vías del perímetro urbano de época romana correspondan a caminos preexistentes que darían acceso al poblado previo y que habrían sido incorporados por la expansión urbana de la nueva civitas $^{9}$. La mayoría de las calzadas documentadas se adapta al perfil de las colinas, buscando el camino más favorable, aunque presentando, en algunos casos, una inclinación bastante acentuada. De hecho, se conocen al menos dos vías, en la zona noroeste, con tramos de escaleras para adaptarse a la pronunciada pendiente -vías XI y XII-.

El terreno está caracterizado por la presencia de diversas colinas de pequeña/mediana dimensión entre las cuales se intercalan algunos valles y zonas más bajas. Dicha morfología implica que los caudales pluviales se acumulaban en estos puntos, que se pueden definir como zonas naturales de acumulación/confluencia de agua ${ }^{10}$. En concreto, es posible identificar tres zonas principales, una correspondiente a la vía II y otras dos, localizadas en el centro del área urbana, que se unen, dando origen a una rivera estacional sobre la que fueron levantados tanto un pequeño puente de un arco -vía $\mathrm{X}$ - como los dos edificios termales de los que hablaremos más adelante.

9 Sousa, op. cit. n. 8, p. 63.

10 Felício, C.: Gestão de resíduos em Mirobriga - $O$ sistema de saneamento. Séculos I-IV d.C. Dissertação de Mestrado em Arqueologia presentada en 2019 en la Faculdade de Ciências Sociais e Humanas da Univ. Nova de Lisboa, pp. 25-26.

Ediciones Universidad de Salamanca / @®@্তি
Todas las calzadas se presentan empedradas con losas de caliza turbítica de tamaños y formas irregulares, salvo en los tramos con escaleras, donde se emplearon bloques pétreos bien escuadrados para conformar los peldaños. Hasta el momento no se han documentado aceras laterales ni pórticos, salvo los porches que, con diferente grado de monumentalización, enmarcan la entrada de la Casa da Hospedaria/Casa 22 (Cortés, 2018: 153) y de la Casa 8 (Oberhofer, 2018). Tampoco existe en Mirobriga un verdadero sistema de evacuación subterráneo, solo utilizado en los complejos termales. Por consiguiente, los residuos líquidos originados en los distintos edificios eran directamente depositados en la superficie de las calzadas, que, a su vez, se encargaban de arrastrar el exceso de líquido que no se infiltraba por los intersticios entre las losas. Este sistema implicaba que tanto las aguas pluviales como las aguas usadas provenientes de las casas, talleres y tabernae confluyeran en la calle, donde la escorrentía se deslizaba gracias a la adaptación de las vías a la inclinación natural del terreno (Fig. 13).

La mayoría de las calzadas presenta un perfil convexo que favorece la concentración de las aguas en sus laterales. La única excepción la ofrece la vía Ix, localizada al oeste de los edificios termales. La excavación de esta esta zona reveló la existencia de un surco longitudinal en la roca, bajo el enlosado viario $^{11}$. A pesar del mal estado de conservación del pavimento, es posible que este surco le confiriera a la calzada un perfil en 'v', haciendo que el líquido en superficie se concentrase en el centro. Dicha depresión longitudinal se dirige hasta el sumidero localizado en el ángulo norte de las Termas Oeste, por lo que su función parece ser la de encauzar la escorrentía hasta conectar con el sistema de evacuación de dicho edificio.

Para evitar la infiltración de las aguas que discurrían por las calles se optó por aplicar gruesos revestimientos de opus signinum en la base de algunas

11 Barata, M. F.: Intervenção arqueológica no muro limite das Termas Oeste. Relatório de escavação inédito realizado en 2002 y depositado en el Arquivo Português de Arqueologia, Direcção Geral do Património Cultural. Processos S-00004 y 98/1(770).

Zephyrus, LXXXVIII, julio-diciembre 2021, 135-161 

frente a la escorrentía superficial en Augusta Emerita (Mérida) y Mirobriga (Santiago do Cacém, Portugal)

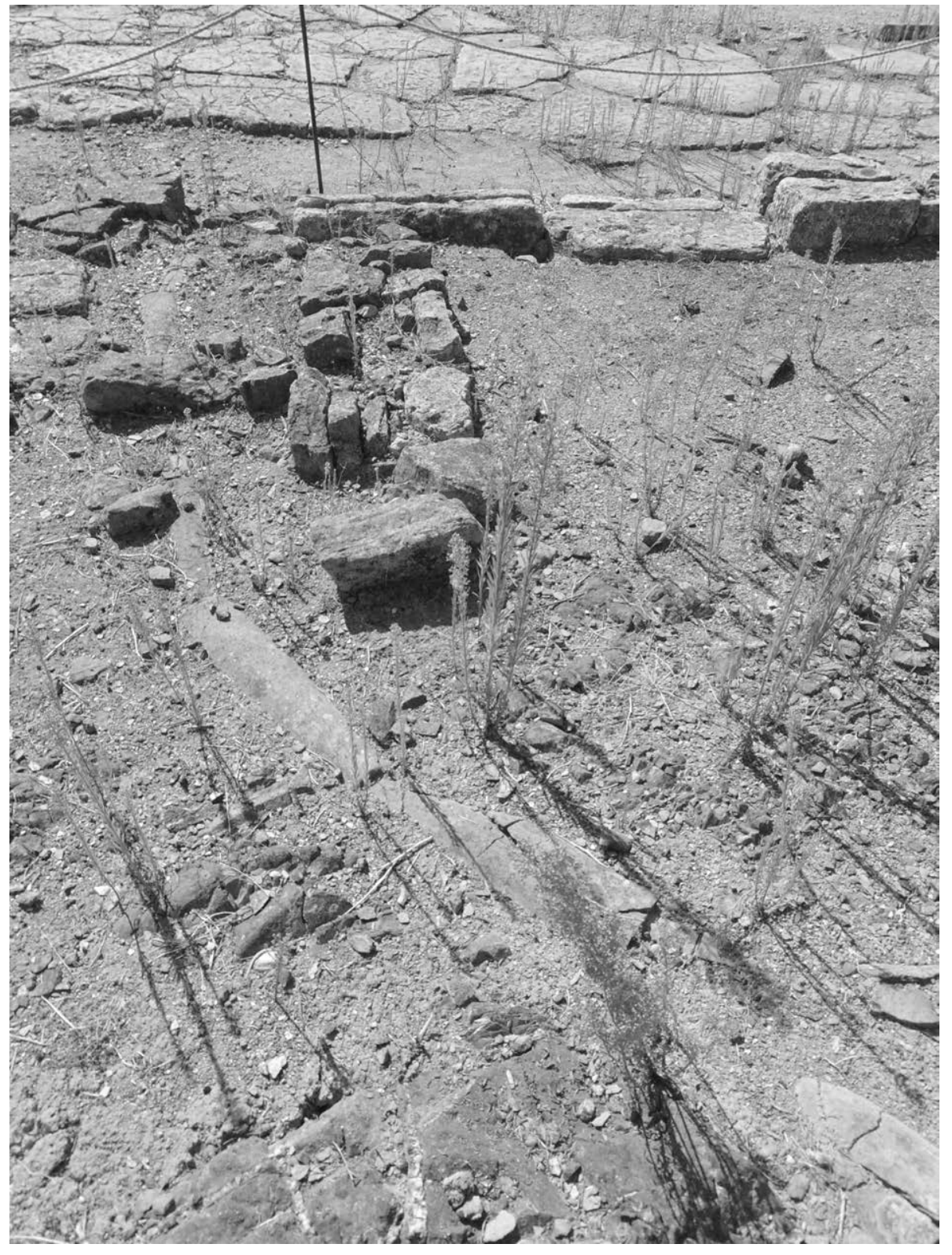

Fig. 13. Punto de vertido de un canal procedente de la Casa da Calçada en la superficie de la vía III de Mirobriga (cortesía de F. Sousa).

fachadas. En concreto se han identificado cuatro casos en espacios domésticos, uno en la taberna de la Casa da Calçada, junto a un punto de desagüe de residuos líquidos de la vivienda (Barata, 1999: 58) ${ }^{12}$; otro en la fachada de la Casa 8 (Oberhofer,

12 También vid. Sousa, op. cit. n. 8, p. 59.
2018: 146), y los dos últimos en sendos edificios aún por excavar situados en la vía III (Barata, 1998: 95). A ellos se suman las rampas de mampostería revocada que, con la misma función, fueron construidas en los edificios termales, tal como veremos más adelante.

Por otro lado, la posición a media ladera de algunos inmuebles también los exponía a la escorrentía del terreno. De ahí que, en algunos de ellos, concretamente en las identificadas como Construcción 1 y 2 (Barata, 1999; Quaresma, 2012), en la Casa Periquito (Kopf, 2018a) y en la Casa 6 (Kopf, 2018b), hayan sido identificadas zanjas en la roca en su parte posterior, creando una distancia de seguridad, con una anchura que varía de 78,2 a 106 $\mathrm{cm}$ y una profundidad de 20 a $104 \mathrm{~cm}$, entre el inmueble y la roca (Fig. 14). Estas depresiones se encontraban revestidas con opus signinum, formando una capa de impermeabilización para proteger el edificio de la infiltración y la humedad. Se creaban así pequeñas trincheras que contornaban cada edificio, encauzando las aguas hacia un punto donde el líquido no provocase dańos ni inconvenientes, probablemente las propias vías urbanas. 



Fig. 14. Zanjas de encauzamiento en Mirobriga: A) Construcción 2 (Arquivo fotográfico de Mirobriga); B) Casa 6 (Kopf, 2018b: fig. 114).

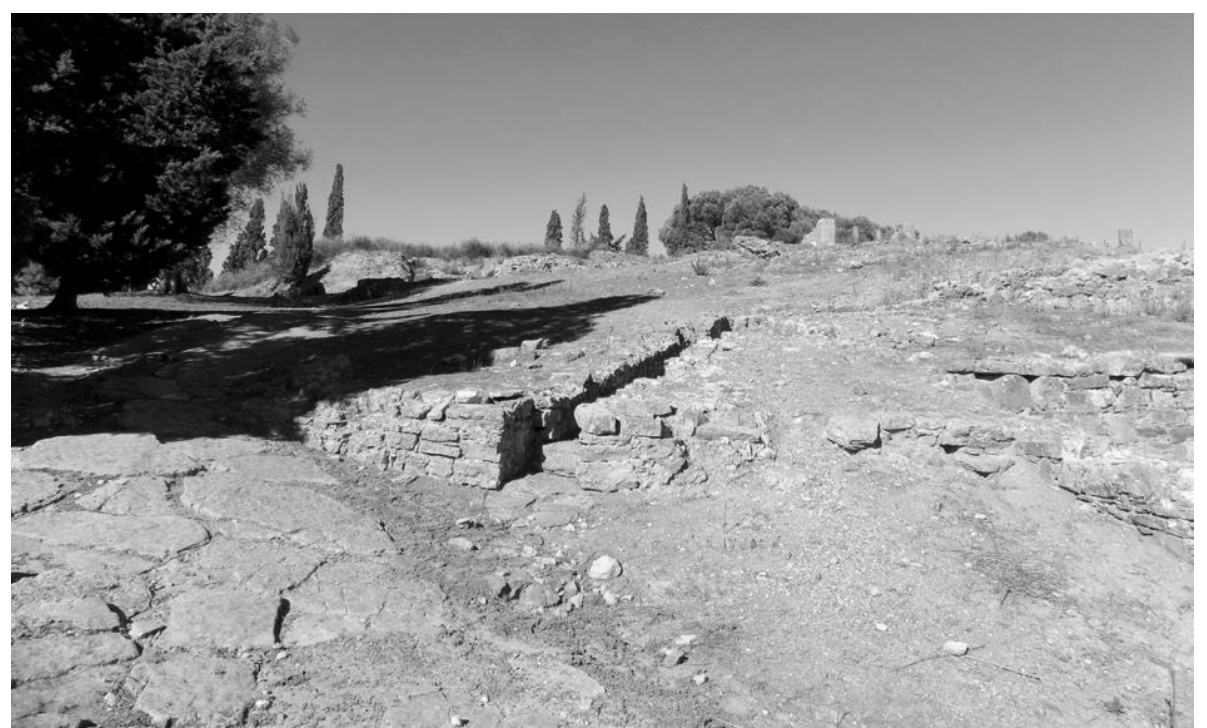

FIG. 15. Canal encargado del drenaje del de la plaza del foro mirobrigense (arriba dcha.) y su punto de vertido junto a la vía IV (izqda.).

\subsubsection{Edificios públicos}

Entre los distintos complejos públicos identificados en Mirobriga destacan el foro, las termas y el circo, este último localizado a cerca de un kilómetro al sur del centro de la ciudad. A estos se suman otros dos inmuebles de función más incierta: el denominado Edificio A, del que luego hablaremos, y otro identificado en los últimos años en un sector aún poco excavado y que podría tratarse de un macellum (Quaresma et al., 2020: 123). Este último, a pesar de que, considerando su morfología, contó muy probablemente con un patio interior que habría necesitado de un sistema de evacuación, no se encuentra aún suficientemente documentado, por lo que habrá que esperar a futuras intervenciones. Tampoco el circo mirobrigense ha proporcionado vestigios de euripus en la spina o de algún sistema de drenaje en la arena, pues se trata de un ejemplar caracterizado por la sencillez de su construcción, aparentemente sin infraestructuras hidráulicas, según demuestran las últimas prospecciones geofísicas realizadas (Teichner, 2018c: 43-44). Nos centraremos, así pues, en los edificios restantes.

Comenzando por el foro, su configuración, constituida por diversos edificios organizados en torno a una plaza porticada, propiciaba que las aquae pluviae que se precipitaban sobre sus tejados confluyeran en la zona central a cielo abierto. Dado que gran parte de las losas del piso de la plaza no se ha conservado, desconocemos si el pavimento alrededor del pórtico presentaría un canal perimetral que recogiera las aguas. No obstante, la capa de preparación, con un mortero semejante al opus signinum, presenta una inclinación general hacia el ángulo sur, punto donde se inicia una canalización subterránea. 

frente a la escorrentía superficial en Augusta Emerita (Mérida) y Mirobriga (Santiago do Cacém, Portugal)

Este conducto es el único identificado en la ciudad que corre por debajo de una calle -vía Xv-, aunque solo en parte de su trazado, en el que, además, se distinguen dos fases constructivas. En origen desaguaría en la vía iv, que delimitaba el lado oeste del complejo forense. Posteriormente, cuando fue construido el denominado Edificio B, en torno a la época de Nerón-Vespasiano (Quaresma et al., 2020: 127), su trazado se prolongó contornando este nuevo inmueble y pasando a desaguar hacia la vía vi, donde dejaba salir el agua en superficie (Fig. 15).

En cuanto a las termas, se conocen dos complejos públicos construidos en contigüidad, con una diferencia cronológica de apenas algunas décadas: las denominadas Termas Este, levantadas a finales del s. I d. C., y las Termas Oeste, a principios del s. II d. C. (Biers y Biers, 1988: 108-115). Su posición en el fondo de un valle se debe a las necesidades de suministro hídrico, que sería proporcionado por un sistema que recogería agua desde un conjunto de fuentes situadas en torno a la rivera allí existente (Slane, 1988: 8; Barata, 1998: 93-94; Quaresma, 2012: 59-63) ${ }^{13}$. Esta localización significó, sin embargo, que estos edificios estuvieran localizados en la convergencia de dos de las zonas de confluencia natural de aguas a las que ya nos hemos referido. La construcción de las Termas Este implicó que parte del cauce de la rivera fuese canalizado, sirviendo, a la vez, como receptáculo de las aguas residuales producidas en el edificio. Las Termas Oeste siguieron la misma estrategia, aunque su implantación supuso la ocupación de la totalidad del cauce aguas arriba del primer complejo termal. Por ello, el sistema de evacuación del nuevo edificio tuvo que incorporar sumideros, situados alrededor del inmueble, destinados a recoger las aguas pluviales procedentes de las zonas de acumulación, concentrándolas en una cloaca y, a su vez, reaprovechando el caudal para la evacuación de las aguas procedentes de las piscinas y las letrinas de ambas termas (Fig. 16).

13 También vid. Reis, M. P.: DE LVSITANIAE VRBIVM BALNEA. Estudo sobre as termas e balneários das cidades da Lusitânia. Tese de Doutoramento em Arqueologia presentada en 2014 en la Faculdade de Letras da Univ. de Coimbra, vol. I, pp. 213-215, así como Felício, op. cit. n. 10, pp. 17-19.

Ediciones Universidad de Salamanca / @(90)
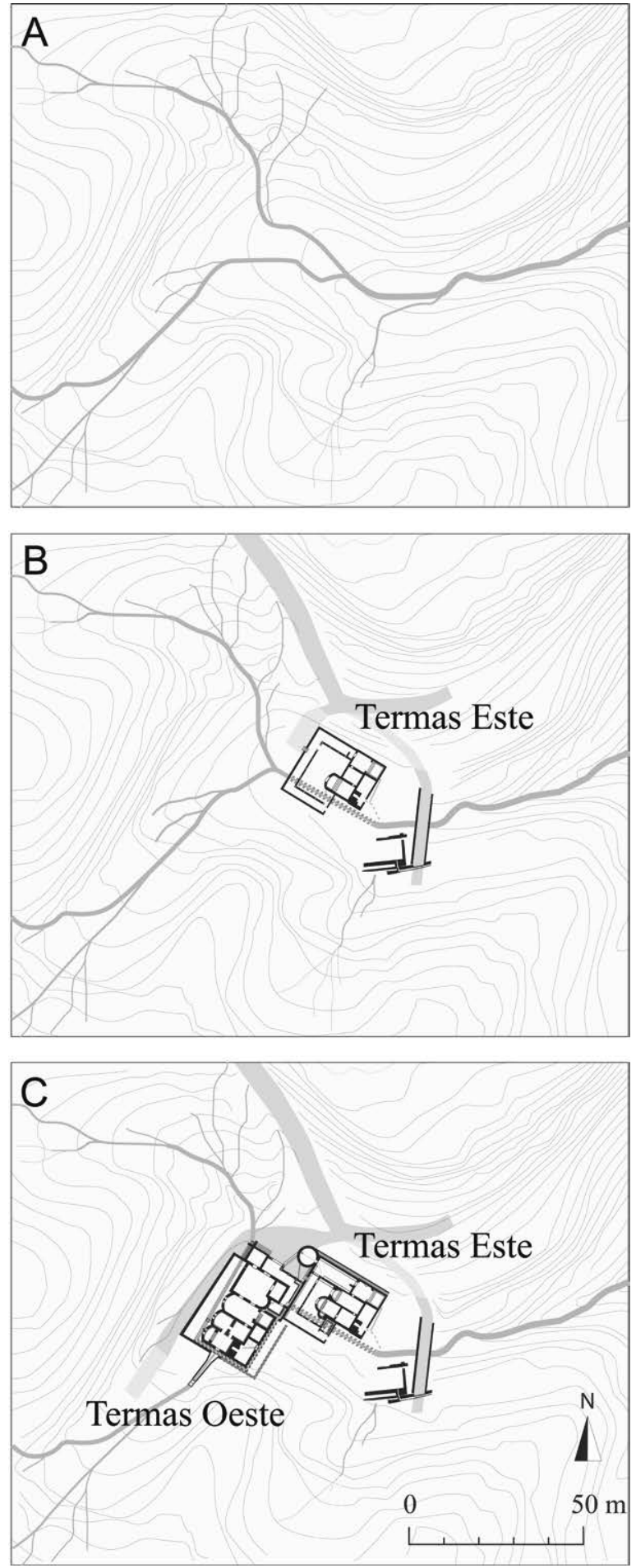

Fig. 16. Sintesis de la implantación en Mirobriga de los edificios termales en la zona de confluencia de aguas (adaptado de Felício y Sousa, 2020: fig. 2).

Zephyrus, LXXXVIII, julio-diciembre 2021, 135-161 

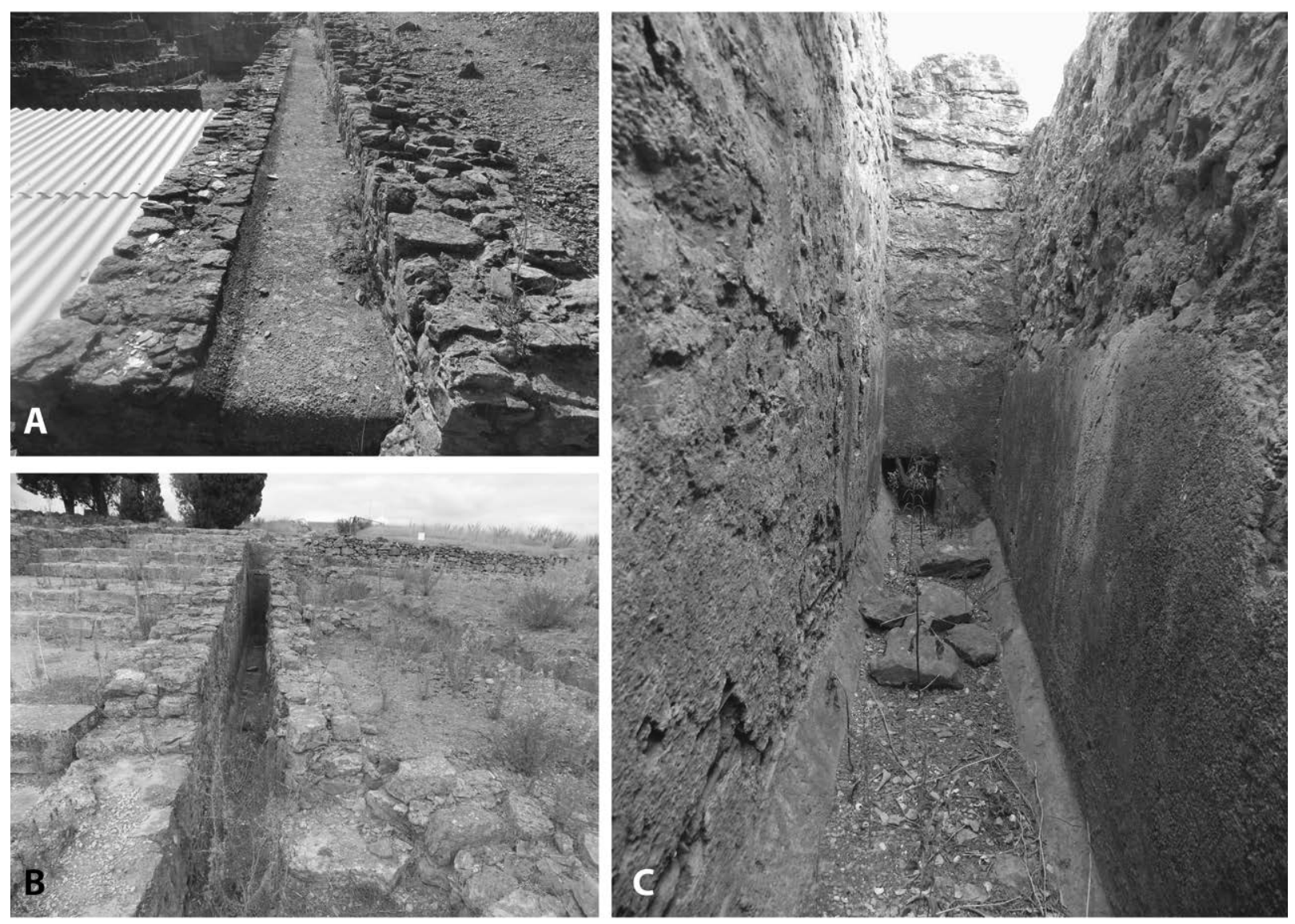

Fig. 17. Paredes dobles en Mirobriga: A) Termas Este; B) Edificio A, en el lado O, delimitado por las escaleras de la vía XI; C) Edificio A, interior del lado $N$.

Aunque ambos inmuebles utilizaron la rivera, el sistema del segundo edificio es más complejo, lo que denota una evolución en el conocimiento del terreno y su comportamiento ${ }^{14}$. Sin embargo, no fue posible canalizar todo el caudal de la rivera hacia la red de evacuación, en particular el proveniente de la ladera existente al $\mathrm{N}$ de los edificios y que era susceptible de damnificarlos. Es por ello que en fases posteriores fueron construidas diferentes estructuras de protección. Así, en las Termas Este, a lo largo del límite norte fue levantada una estructura de paredes dobles, con una anchura máxima de $98 \mathrm{~cm}$, impermeabilizada con opus signinum (Fig. 17A), además de

14 Para más detalles sobre este sistema y, en general, sobre la evacuación hídrica en ambos edificios termales, véase Felício y Sousa (2020).

Ediciones Universidad de Salamanca / 요요 una rampa de mampostería, también recubierta de mortero hidráulico, adosada a la fachada junto al acceso al inmueble. En una reforma posterior se colocó delante de la entrada una pequeña barrera o resalto de ladrillos con revestimiento de opus signinum, de $15-20 \mathrm{~cm}$ de altura, que desviaba la escorrentía y la encauzaba hacia un sumidero conectado con el colector principal del edificio ${ }^{15}$. Por su parte, las Termas Oeste contaron desde el inicio con otras dos rampas de impermeabilización protegiendo el ángulo norte (Biers y Biers, 1988: 110) y ayudando, a la vez, a dirigir la escorrentía hacia un sumidero que drenaba el agua de esta importante zona de acumulación.

15 Felício, op. cit. n. 10, pp. 109-110.

Zephyrus, LXXXVIII, julio-diciembre 2021, 135-161 
Por último, hay que referirse al identificado como Edificio A, posiblemente público, si bien la fragmentaria extensión documentada hasta ahora no permite atribuirle una función concreta. Pese a ello, la parte ya descubierta proporciona datos de interés en cuanto a su exposición a las aguas llovedizas y a su protección frente a ellas. Así, los restos visibles evidencian que el edificio fue construido contra una ladera, encontrándose rodeado por vías en tres de sus lados. La vía I, por detrás del edificio, se sitúa a una altura más elevada respecto a la cota de circulación interna del inmueble, mientras que las vías XI y XII corresponden a escalinatas que descienden hacia la parte delantera del edificio, donde se ubicaría la entrada, aunque esta se encuentra aún por excavar. Dicha configuración propiciaba que tanto la escorrentía superficial como la propia humedad existente en el terreno afectasen a los paramentos del edificio. Este problema ya habría sido previsto desde su construcción, ya que el inmueble se encuentra aislado respecto a las tres vías que lo circundan a través de un sistema de paredes dobles (Fig. 17B-C). El hueco interno, que no es homogéneo en los tres flancos ${ }^{16}$, se presenta impermeabilizado con opus signinum, dotado de media caña en las juntas, así como pequeños dinteles colocados transversalmente para reforzar la estabilidad de ambas paredes. El lado norte presenta, además, tres contrafuertes que sirven de soporte a la vía i y que constan de una abertura en su base para no interrumpir el paso del flujo acumulado en el interior. La pendiente dirigía el líquido desde los extremos este y oeste hacia la fachada sur, en dirección al valle, aunque la mala conservación de esta parte delantera del edificio, prácticamente por excavar, impide conocer su configuración.

16 La anchura es de 55-60 cm en los lados norte y este, mientras que en el flanco oeste, donde se observan indicios de reforma, alcanza los 38-40 cm (Felício, op. cit. n. 10, p. 67).

Ediciones Universidad de Salamanca / 요요

\section{Síntesis comparativa}

Los datos expuestos muestran dos modelos diferentes en la evacuación, no solo de la escorrentía, sino de las aguas residuales en general: el sistema de drenaje subterráneo, en Augusta Emerita, basado en la existencia de una red de cloacas bien articulada, extendida por todo el tejido urbano, y el sistema de drenaje superficial, en Mirobriga, donde eran las propias calles las que recibían y encauzaban la mayor parte de los residuos líquidos. Esto implica que el propio contenido de la escorrentía en las vías de cada ciudad sería diferente, pues en el primer caso estaba compuesta, básicamente, por el agua de lluvia $y$, probablemente, por el agua sobrante de las fuentes públicas, mientras que en el segundo se añadían las aguas sucias procedentes de los inmuebles aledaños a las calles ${ }^{17}$.

En la Fig. 18 se recoge la presencia/ausencia de las principales estructuras ligadas a la evacuación de las aguas superficiales en las vías y en los edificios públicos aquí analizados. En ella se comprueba el variado elenco de elementos de drenaje utilizados en Augusta Emerita, en consonancia con la existencia de una red subterránea de saneamiento, mientras que en Mirobriga se impone la presencia de las estructuras de aislamiento e impermeabilización en el contorno de los inmuebles.

Ambas ciudades contaron con calles empedradas y dotadas de un perfil alomado, desviando la escorrentía hacía los laterales para dejar un espacio en el centro más favorable al tránsito ${ }^{18}$. No obstante, la presencia generalizada de aceras porticadas en la colonia emeritense marcaba una diferencia sustancial para los peatones, que de esta manera quedaban

17 No parece, en todo caso, que se incluyan en ellas las aguas fecales. Aquellos canales en los que es posible determinar su origen proceden de los patios domésticos o de otras estancias de uso productivo/comercial, no de instalaciones sanitarias. Las dos únicas letrinas conocidas en Mirobriga, localizadas en las Termas Este y Oeste, estaban conectadas con el sistema de cloacas de estos edificios (Felício, op. cit. n. 10, pp. 91-98).

18 Apenas contamos con un ejemplo en cada ciudad con un perfil cóncavo: la vía anular del teatro de Mérida y la vía IX en Mirobriga. 

frente a la escorrentía superficial en Augusta Emerita (Mérida) y Mirobriga (Santiago do Cacém, Portugal)

\begin{tabular}{|c|c|c|c|c|}
\hline & & & AUGUSTA EMERITA & MIROBRIGA \\
\hline \multirow{11}{*}{ Vías } & \multicolumn{2}{|l|}{ enlosados pétreos } & $\mathrm{x}$ & $\mathrm{x}$ \\
\hline & \multicolumn{2}{|l|}{ sección alomada } & $\mathrm{x}$ & $\mathrm{x}$ \\
\hline & \multicolumn{2}{|l|}{ aceras y pórticos } & $\mathrm{x}$ & - \\
\hline & \multicolumn{2}{|l|}{ bajantes } & $\mathrm{x}$ & - \\
\hline & \multicolumn{2}{|l|}{ bocas de registro } & $\mathrm{x}$ & $\mathrm{x}$ \\
\hline & \multicolumn{2}{|l|}{ imbornales } & $\mathrm{x}$ & - \\
\hline & \multicolumn{2}{|l|}{ canales de desagüe } & $\begin{array}{c}\mathrm{x} \\
\text { (desde imbornales e inmuebles } \\
\text { aledaños a cloacas) }\end{array}$ & $\begin{array}{c}\mathrm{x} \\
\text { (desde inmuebles aledaños a vías) }\end{array}$ \\
\hline & \multicolumn{2}{|l|}{ cloacas } & $\mathrm{x}$ & - \\
\hline & \multirow{3}{*}{$\begin{array}{l}\text { estructuras de } \\
\text { aislamiento en } \\
\text { fachadas }\end{array}$} & $\begin{array}{l}\text { estructuras de } \\
\text { impermeabilización }\end{array}$ & $\mathrm{x}$ & $\mathrm{x}$ \\
\hline & & zanjas de encauzamiento & - & $\mathrm{x}$ \\
\hline & & paredes dobles & - & $\mathrm{x}$ \\
\hline \multirow{11}{*}{$\begin{array}{l}\text { Edificios } \\
\text { Públicos }\end{array}$} & \multirow{5}{*}{$\begin{array}{l}\text { grandes recintos } \\
\text { porticados }\end{array}$} & canales perimetrales & $\mathrm{x}$ & - \\
\hline & & bajantes & $\mathrm{x}$ & - \\
\hline & & sumideros & $\mathrm{x}$ & $\mathrm{x}$ \\
\hline & & canales de desagüe & $\mathrm{x}$ & $\mathrm{x}$ \\
\hline & & cloacas & $\mathrm{x}$ & - \\
\hline & \multirow[t]{6}{*}{ otros edificios } & barreras/resaltos & - & $\begin{array}{c}\mathrm{x} \\
\text { (Termas Este) }\end{array}$ \\
\hline & & sumideros & $\begin{array}{c}\mathrm{x} \\
\text { (Teatro, Anfiteatro y Circo) }\end{array}$ & $\begin{array}{c}\mathrm{x} \\
\text { (Termas Este y Oeste) }\end{array}$ \\
\hline & & $\begin{array}{l}\text { canales/canaletas } \\
\text { de desagüe }\end{array}$ & $\begin{array}{c}\mathrm{x} \\
\text { (Teatro, Anfiteatro y Circo) }\end{array}$ & $\begin{array}{c}\mathrm{x} \\
\text { (Termas Este y Oeste) }\end{array}$ \\
\hline & & cloacas & $\begin{array}{c}\mathrm{x} \\
\text { (Teatro y Anfiteatro) }\end{array}$ & $\begin{array}{c}\mathrm{x} \\
\text { (Termas Este y Oeste) }\end{array}$ \\
\hline & & bocas de registro & $\begin{array}{c}\mathrm{x} \\
\text { (Teatro) } \\
\end{array}$ & $\begin{array}{c}\mathrm{x} \\
\text { (Termas Oeste) }\end{array}$ \\
\hline & & $\begin{array}{l}\text { encauzamiento de } \\
\text { vaguadas/riveras }\end{array}$ & $\begin{array}{c}\mathrm{x} \\
\text { (Circo) }\end{array}$ & $\begin{array}{c}\mathrm{x} \\
\text { (Termas Este y Oeste) }\end{array}$ \\
\hline
\end{tabular}

FIG. 18. Cuadro-resumen de las estructuras de drenaje y aislamiento documentadas en Augusta Emerita y Mirobriga.

protegidos tanto del agua que caía en forma de lluvia como de la escorrentía que se generaba en las calzadas. En las calles de esta ciudad dos tipos de aberturas permitían la evacuación del agua en superficie hacia las cloacas subterráneas:

A) Los imbornales, específicamente diseñados con este objetivo y situados generalmente en los laterales de las calles (conectados con canales secundarios que conducían el agua hacia la cloaca central) o, en casos puntuales, directamente sobre el colector principal ${ }^{19}$. La ubicación de algunos en coincidencia con las columnas de los pórticos viarios indica que también recogían el agua

19 En otras ciudades la presencia de un sistema de cloacas no implica necesariamente la existencia o profusión de imbornales. Para las urbes del conventus Tarraconensis Romaní (2019: 335-336) plantea, considerando el escaso número de imbornales documentados y la superficialidad a la que discurrían las cloacas, que la evacuación de la escorrentía se realizaría directamente por infiltración, sin necesidad de contar con estructuras que la encauzasen hacia los colectores subterráneos. 
procedente de la techumbre de los pórticos, a través de tuberías bajantes que no se han conservado ${ }^{20}$.

B) Las bocas de registro de las cloacas, que, a pesar de estar cubiertas con losas pétreas, permitían la infiltración de cierta cantidad de agua hacia su interior. No se conocen, sin embargo, tapas perforadas, tan frecuentes en otras muchas ciudades y que sumaban a la función principal de estas estructuras -el acceso a las cloacas- otra utilidad suplementaria como sumideros/imbornales.

La progresiva privatización de los pórticos viarios, no obstante, conllevó el adelantamiento de las fachadas prediales hasta el límite de las calzadas, lo que provocó dos consecuencias esenciales: por un lado, obligó a los peatones a transitar por la zona inicialmente reservada al tráfico, quedando desprotegidos de los agentes atmosféricos, y, por otro, expuso las fachadas directamente a la escorrentía. Es por ello que, en determinados lugares, especialmente en los tramos con escasa inclinación, más propensos al estancamiento de las aguas, hubo que proteger la base de los muros frente a la humedad, aunque hasta el momento solo conocemos dos ejemplos ya referidos, uno en el que se aplicó un refuerzo de mampostería y otro con un simple revestimiento de opus signinum. Por otra parte, la proliferación de los pavimentos de tierra en época tardoantigua repercutió en la capacidad drenante de las vías emeritenses, al crear superficies de perfil más plano, taponar los imbornales y favorecer la colmatación de las cloacas. Con el paso del tiempo, por tanto, tendieron a igualarse las condiciones de drenaje en las calles de ambas ciudades, así como la propia experiencia de los viandantes al transitar por ellas.

En Mirobriga el callejero se mantuvo sin grandes cambios $^{21}$, siempre caracterizado por la ausencia de

20 Una situación similar se documenta, por ejemplo, en el sitio del Verbe Incarné, en Lyon (Chomer y Thirion, 2008: 240-242).

21 Es posible que también aquí el pavimento de las vías pasase a ser de tierra a partir de los ss. III-IV d. C., momento en el que la ciudad entró en una clara fase de decaimiento

Ediciones Universidad de Salamanca / 요 un sistema subterráneo de evacuación. La configuración de las colinas y del trazado viario favorecían el drenaje natural del terreno, motivo por el que, probablemente, se consideró que no compensaba el esfuerzo constructivo y económico de instalar una red de saneamiento, solo reservada para las termas. Se trata de un fenómeno poco habitual en el contexto de la provincia de Lusitania, donde incluso ciudades con un limitado desarrollo urbanístico cuentan con colectores viarios, aunque sean estructuras de escasa entidad constructiva (Acero, 2019: 158). El modelo mirobrigense, en realidad, es similar al de ciudades como Pompeya, donde se privilegia la evacuación superficial de las aguas residuales, reservando las cloacas apenas para solucionar el desagüe de determinados edificios públicos (Koga, 1992; Jansen, 2002: 63-68; Poehler, 2012). No obstante, en la pequeña localidad lusitana el sistema de drenaje es mucho más simple, puesto que aquí no existen aceras, ni pasos sobreelevados para peatones, ni muchos de los variados recursos -bordillos, resaltos, badenes, etc.- utilizados en la ciudad vesubiana para dirigir el líquido hacia las zonas más favorables, hasta salir fuera de la ciudad ${ }^{22}$.

En Mirobriga este sistema de evacuación superficial no traería grandes problemas durante los períodos estivales, aparte del probable mal olor de las aguas procedentes de los espacios domésticos y artesanales, además de la proliferación de mosquitos en torno a las aguas estancadas, favoreciendo la transmisión de enfermedades. En términos funcionales los mayores inconvenientes vendrían ocasionados las estaciones lluviosas, cuando, debido a la ausencia de drenaje, los caudales pluviales fluirían por las vías y por las laderas del terreno hasta los puntos más bajos de la ciudad. Es en estas zonas, más expuestas a la acumulación de aguas, donde se concentra un considerable número de estructuras de aislamiento para proteger a los edificios de la humedad y de las

urbanístico, aunque se trata de una cuestión todavía en abierto por falta de estratigrafías apuradas.

22 La única excepción es la mencionada barrera o resalto correspondiente a una reforma para proteger de la escorrentía la entrada de las Termas Este, encauzando el flujo hacia la red de desagüe del edificio. 




Fig. 19. Diseño esquematizado de las estructuras de aislamiento documentadas en Mirobriga.

infiltraciones y que pueden agruparse en tres tipos (Fig. 19):

A) Estructuras de impermeabilización. Son elementos que sirven de barrera en la base de las fachadas para protegerlas del agua en superficie. Las más complejas se localizan en los dos edificios termales y consisten en rampas de mampostería recubiertas de opus signinum (Fig. 20A). Las más sencillas son simples revestimientos de mortero hidráulico de gran espesor y con un perfil ligeramente inclinado o en forma de media caña (Fig. 20B). Aunque este tipo de estructura, sea a modo de rampa o de revestimiento, se conoce en otras ciudades (Fig. 20C-F), no aparece con la

Ediciones Universidad de Salamanca / @®্ত profusión que se detecta en Mirobriga ${ }^{23}$, lo que revela las condiciones particulares que sufrió este lugar frente a la escorrentía.

B) Zanjas de encauzamiento. Son cortes longitudinales en la roca, no localizados a lo largo de las vías, sino junto a los muros traseros de determinados inmuebles implantados a media ladera, los más expuestos a la escorrentía que se deslizaba por las vertientes del terreno. En algunos tramos se presentan impermeabilizados en su base con una capa de opus signinum. Todos los casos documentados se localizan en inmuebles privados (vid. supra Fig. 15).

C) Paredes dobles. Estructuras formadas por el muro delimitador de un edificio antecedido por una pared paralela a escasa distancia -entre 38 y $98 \mathrm{~cm}$-. El espacio de separación queda impermeabilizado con opus signinum, tanto en el suelo como en los paramentos. En los dos casos conocidos, ambos en edificios públicos -Termas Este y Edificio A-, se sitúan en los flancos más expuestos a la escorrentía de las laderas del terreno (vid. supra Fig. 17). Por su morfología este tipo de estructura se asemeja a las soluciones empleadas en criptopórticos que refiere Giuliani (2006: 158, fig. 12), así como a la descripción que ofrece Vitruvio (De Arch. 7. 4. 1) para la construcción de paredes dobles en lugares de gran humedad. No obstante, las condiciones de conservación de los dos casos mirobrigenses impiden concretar cómo se resolvería el remate superior, por lo que se pueden plantear dos hipótesis: o bien que existiera una cubierta, de modo que el espacio interno funcionase como una cámara estanca para acumular

23 En Hispania, aparte de los dos casos citados de $A u$ gusta Emerita, se conocen ejemplos aislados en la fachada posterior del Edificio del Atrio, en Carthago Nova (Noguera et al., 2009: 76, lám. 37) y al sur de la Casa de la Cañada Honda, en Italica, aunque en este caso aplicado sobre el bordillo de la acera y no directamente sobre la fachada (Luzón, 1982: lám. v.3). Más abundantes son los casos conocidos en Pompeya, una ciudad cuyo sistema de drenaje, como ya se ha dicho, también se basa en la evacuación superficial de las aguas. 
J. Acero Pérez y C. Felício / Aquae pluviae et caducae. Sistemas de drenaje e impermeabilización frente a la escorrentía superficial en Augusta Emerita (Mérida) y Mirobriga (Santiago do Cacém, Portugal)
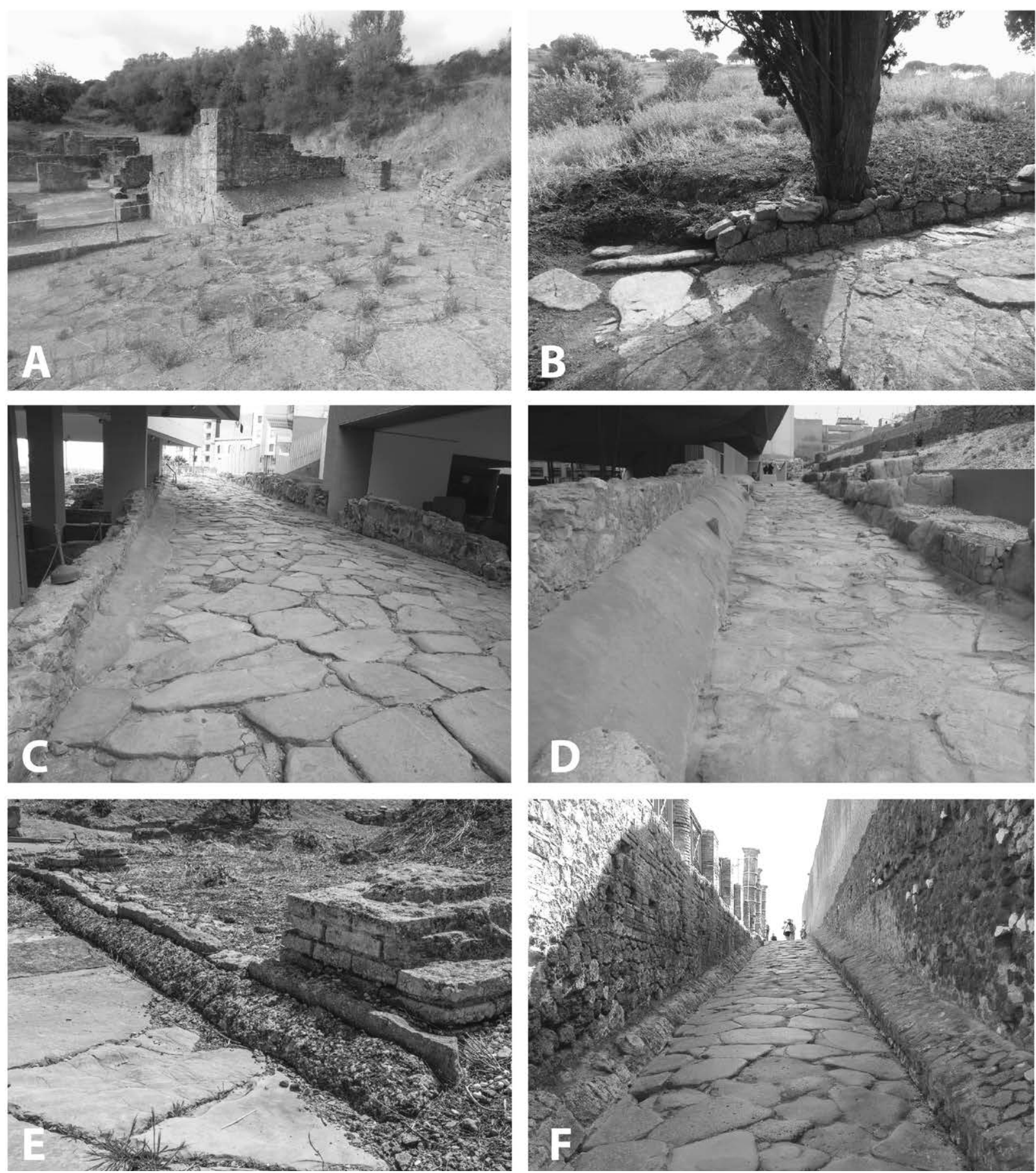

FIG. 20. Estructuras de impermeabilización: A) Termas Oeste de Mirobriga; B) Edificio aún por excavar en la vía III de Mirobriga; C) Casa de los Mármoles de Augusta Emerita; D) Edificio del Atrio, Carthago Nova; E) Cañada Honda, Italica (D. González Acuña, Conjunto Arqueológico de Italica); F) Via di Porta Marina de Pompeya. 
la percolación, o bien que fuese un espacio abierto, actuando de manera semejante a las zanjas de encauzamiento.

En cuanto a los edificios públicos, tanto el diferente grado de monumentalidad como la existencia o no de un sistema de cloacas influyeron en los mecanismos de evacuación implantados en cada una de las ciudades analizadas. En el caso de los grandes recintos porticados emeritenses se detectan tres mecanismos de evacuación del agua de lluvia: bajantes -al menos en templos-, canales perimetrales al pie de los pórticos -ya sean cubiertos o descubiertos- $y$ sumideros para encauzar la escorrentía en la superficie de las áreas abiertas. El líquido acababa siendo derivado hacia canales subterráneos conectados con la red pública de alcantarillado. En cambio, el foro de Mirobriga no ha proporcionado restos de bajantes ni de canal perimetral. Solo un sumidero, en el ángulo suroeste del recinto, permitía el drenaje de la plaza, conectando con un conducto que vertía el líquido en la superficie de una calle próxima.

No es posible la comparación de ambos núcleos urbanos en lo que respecta a los edificios de espectáculos, pues en Mirobriga solo se conoce el circo, un edificio de escasa entidad constructiva que no ha proporcionado restos de infraestructuras hidráulicas. En cambio, en Augusta Emerita, tanto el circo como el teatro y el anfiteatro, todos ellos con un elevado grado de conservación, ofrecen elementos que reflejan la preocupación por facilitar el drenaje. En el primero debido, sobre todo, a la presencia de una pequeña vaguada en la mitad oriental que hubo que canalizar, aparte del agua contenida en los euripi de la spina. En el teatro y el anfiteatro, por su parte, la estrategia de desagüe se orientó a cumplir dos objetivos básicos: evitar el encharcamiento de las principales zonas de paso $\mathrm{y}$, sobre todo, evacuar, a través de sendas cloacas, el agua que se acumulaba en las zonas bajas de los edificios, es decir, la orchestra y la fossa arenaria respectivamente. No existen, sin embargo, canalizaciones repartidas bajo las gradas para encauzar el agua en los diferentes sectores de la cavea, salvo en la proedria del teatro, elementos que sí se detectan en otros edificios del mismo género con sistemas de desagüe más complejos.

Ediciones Universidad de Salamanca / @®@্তি
Sí comparten ambas ciudades lusitanas el problema particular de emplazar determinados edificios públicos en zonas de rivera o de vaguada cuyas aguas fue necesario canalizar para permitir su implantación. Así sucedió en el circo emeritense, ya comentado, y en los dos complejos termales mirobrigenses. El caso de estos últimos es particularmente significativo. Su emplazamiento sobre una rivera parece totalmente intencionado, pues sacaba provecho tanto para el abastecimiento hídrico, a partir de diferentes manantiales existentes en la zona, como para la evacuación. Las aguas de su cauce fueron ingeniosamente canalizadas, sirviendo de desagüe de las piscinas y letrinas existentes en ambos edificios. No obstante, al tratarse de una zona topográficamente baja, de confluencia natural de las aguas, los edificios quedaron expuestos a los torrentes pluviales generados en las laderas, que hubo que combatir con estructuras de aislamiento en las zonas más vulnerables de sus fachadas y con sumideros conectados con las cloacas subterráneas. En este sentido, las Termas Oeste, además de estar más evolucionadas desde un punto de vista arquitectónico, denotan un sistema más complejo de evacuación frente a la escorrentía natural, multiplicando la instalación de sumideros alrededor del edificio para canalizar el líquido hacia el colector principal.

\section{Consideraciones finales}

Aunque las ciudades romanas participaron de unos mismos principios urbanísticos e ingenieriles, su materialización se adaptó a realidades muy diversas, tanto en términos físicos como históricos. Prueba de ello la encontramos en los dos núcleos lusitanos aquí analizados. La colonia emeritense, capital provincial, constituye uno de los máximos exponentes del desarrollo alcanzado por el urbanismo y la ingeniería romana en suelo hispano. Fundación ex novo, fue planificada siguiendo el modelo racional de un callejero ortogonal, en el que una red integral de saneamiento, al menos en el espacio intramuros, permitía la evacuación de todos los residuos líquidos generados en la ciudad, incluidas las aguas

Zephyrus, LXXXVIII, julio-diciembre 2021, 135-161 
pluviales. Por su parte, en Mirobriga, una pequeña aglomeración urbana de origen prerromano, se optó por un sistema superficial de eliminación basado en la adaptación de su viario a las pendientes naturales. Esto debió ocasionar no pocas incomodidades, no ya solo para transitar por sus empinadas calles los días de lluvia, sino incluso para la propia conservación de las fachadas aledañas. De ahí que hubiese que recurrir a diferentes mecanismos de aislamiento para evitar la infiltración del agua y la humedad. Estas diferencias iniciales entre ambos núcleos, no obstante, tendieron a igualarse con el devenir del tiempo, especialmente cuando las transformaciones que afectaron al viario emeritense ocasionaron una merma de su capacidad drenante.

\section{Fuentes antiguas}

Plinio Secundo, C.: Historia Natural. Libros III-VI. Traducción de Fontán, A.; García, I.; Del Barrio, E. y Arribas, M. L. (1998). Biblioteca Clásica Gredos, 250. Madrid: Gredos.

Ptolomeo, C.: Geographia. Traducción de Stevenson, E. L. (1991). New York: Dover Publications.

Vitruvio Polión, M.: De Architectura. Traducción de Corso, A. y Romano, E. y edición de Gros, P. (1997). Torino: Giulio Einaudi editore.

\section{Bibliografía}

Acero, J. (2018): La gestión de los residuos en Augusta Emerita: ss. I a. C.-VII d. C. Anejos de Archivo Español de Arqueología, 82. Madrid: Csic.

Acero, J. (2019): "O ciclo urbano da água no Portugal Romano", Anais Leirienses-Estudos \& documentos, 4 , pp. 137-168.

Alba, M. (2001a): "Apuntes sobre la red de aguas de Mérida en época romana”, Mérida. Ciudad y Patrimonio. Revista de Arqueología, Arte y Urbanismo, 5 , pp. 59-78.

Alba, M. (2001b): "Características del viario urbano de Emerita entre los ss. I y vin", Mérida. Excavaciones Arqueológicas 1999. Memoria, 5, pp. 397-423.

AlbA, M. (2002): “Datos para la reconstrucción diacrónica del paisaje urbano de Emerita: las calles porticadas

Ediciones Universidad de Salamanca / 요 desde la etapa romana a la visigoda", Mérida. Excavaciones Arqueológicas 2000. Memoria, 6, pp. 371-396.

Ayerbe, R. (2019): "La porticus post scaenam del teatro de Augusta Emerita. Intervenciones arqueológicas realizadas en el peristilo del teatro romano de Mérida”, Mérida. Excavaciones Arqueológicas 2009-2011, 13, pp. 53-133.

Ayerbe, R.; Barrientos, T. y Palma, F. (2009): “Arquitectura, configuración y restitución de los recintos monumentales". En Ayerbe, R.; Barrientos, T. y Palma, F. (eds.): El Foro de Augusta Emerita. Génesis y evolución de sus recintos monumentales. Anejos de Archivo Español de Arqueología, 53. Mérida: CsicIAM, pp. 667-806.

Ayerbe, R. y Márquez, J. (1998): "Intervención arqueológica en el solar de la calle Cabo Verde. Espacio funerario del sitio del Disco", Mérida. Excavaciones Arqueológicas 1996. Memoria, 2, pp. 135-166.

Barata, M. F. (1998): "Miróbriga: sua valorização e caracterizaçáo", Anales de Arqueología Cordobesa, 9, pp. 59-129.

Barata, M. F. (1999): "As habitaçóes de Mirobriga e os ritos domésticos romanos", Revista Portuguesa de Arqueologia, 2 (2), pp 51-68.

Barrientos, T. (2006): "Evolución del trazado viario romano extramuros junto a la puerta norte. Intervención arqueológica realizada en la calle Augusto, n. ${ }^{\circ} 4$ (Mérida)", Mérida. Excavaciones Arqueológicas 2003. Memoria, 9, pp. 37-59.

Biers, W. R. (ed.) (1988): Mirobriga. Investigations at an Iron Age and Roman site in southern Portugal by the University of Missouri-Columbia, 1981-1986. BAR Intern. Ser., 451. Oxford: Archaeopress.

Biers, W. R. y Biers, J. C. (1988): "The Baths". En Biers, W. R. (ed.): Mirobriga. Investigations at an Iron Age and Roman site in southern Portugal by the University of Missouri-Columbia, 1981-1986. BAR Intern. Ser., 451. Oxford: Archaeopress, pp. 48-125.

Biers, W. R.; Biers, J. C. y Soren, D. (1982): "Excavations at Mirobriga, The 1982 Season", Mvse, 16, pp. 29-43.

Chomer, C. y Thirion, P. (2008): "L'eau dans la rue de la Fontaine au Clos du Verbe Incarné (Lyon 5e)", En Ballet, P.; Dieudonné-Glad, N. y Saliou, C. (dirs.): La rue dans l'Antiquité. Définition, aménagement et devenir de l'Orient méditerranéen à la Gaule. Rennes: Presses Universitaires de Rennes, pp. 237246.

Cortés, A. (2018): "The Roman houses of flavian $M i$ robriga and their evolution. A first approximation of

Zephyrus, LXXXVIII, julio-diciembre 2021, 135-161 
the archaeological remains". En Teichner, F. (ed.): Mirobriga. Eine Stadt im fernen Westen des Imperium Romanum. Kleine Scriften, 62. Marburg: Vorgeschichtliches Seminar der Philipps-Univ. Marburg, pp. 148-155.

EnCARNAÇÃo, J. D' (1996): "Problemas em aberto na epigrafia mirobriguense", Conimbriga, 35, pp. 129146.

Felício, C. y Sousa, F. (2020): “O fim do ciclo. Saneamento e Gestão de Resíduos nos Edifícios Termais de Mirobriga". En Morais, J.; Neves, C. y Martins, A. (coords.): Arqueologia em Portugal 2020-Estado da Questão. Lisboa: Associação dos Arqueólogos Portugueses/CitceM, pp. 1385-1397. Dor: https://doi. org/10.21747/978-989-8970-25-1/arqa102

Floriano, A. C. (1944): "Excavaciones en Mérida (campañas de 1934 y 1936)", Archivo Español de Arqueologia, 54, pp. 151-186.

García Marín, R. y Mateos, A. B. (2010): "El clima de Extremadura". En Schnabel, S.; Lavado, J. F.; Gómez Gutiérrez, A. y García Marín, R. (eds.): Aportaciones a la geografía física de Extremadura con especial referencia a las dehesas. Cáceres: Fundicotex, pp. 25-52.

Gijón, M. ${ }^{a}$ E. y Montalvo, A. M. (2011): "El circo romano de Mérida”. En Álvarez Martínez, J. M. y Mateos, P. (eds.): Actas del Congreso Internacional "1910-2010. El Yacimiento Emeritense". Mérida, pp. 195-208.

Giuliani, C. F. (2006): L'edilizia nell'antichità (2. $\left.{ }^{\mathrm{a}} \mathrm{ed}.\right)$. Roma: Carocci editore.

Jansen, G. C. M. (2002): Water in de Romeinse stad: Pompeii-Herculaneum-Ostia. Leuven: Peeters.

Koga, M. (1992): "The surface drainage system of Pompeii”, Opuscula Pompeiana, 2, pp. 57-72.

Kopf, J. (2018a): "Archäologische und stratigraphische Untersuchungen zu Haus 5”. En Teichner, F. (ed.): Mirobriga. Eine Stadt im fernen Westen des Imperium Romanum. Kleine Scriften, 62. Marburg: Vorgeschichtliches Seminar der Philipps-Univ. Marburg, pp. 58-91.

Kopf, J. (2018b): “Archäologische und stratigraphische Untersuchungen zu Haus 6”. En Teichner, F. (ed.): Mirobriga. Eine Stadt im fernen Westen des Imperium Romanum. Kleine Scriften, 62. Marburg: Vorgeschichtliches Seminar der Philipps-Univ. Marburg, pp. 92-108.

Luzón, J. M. (1982): "Consideraciones sobre la urbanística de la Ciudad Nueva de Itálica". En Actas de las Primeras Jornadas sobre excavaciones arqueológicas en
Itálica. Excavaciones Arqueológicas en España, 121. Madrid: Ministerio de Cultura, pp. 77-95.

Mateos, P. (2006): "Excavaciones en el solar de las cl Almendralejo y Holguín”. En Mateos, P. (ed.): El "Foro Provincial" de Augusta Emerita: un conjunto monumental de culto imperial. Anejos de Archivo Español de Arqueología, 42. Madrid: csic, pp. 68-118.

Mateos, P. (2011): “Topografía y urbanismo en Augusta Emerita”. En Álvarez Martínez, J. M. y Mateos, P. (eds.): Actas del Congreso Internacional "19102010. El Yacimiento Emeritense”. Mérida, pp. 127144.

Mateos, P. y Pizzo, A. (2006): "Intervención arqueológica en el solar ocupado por los restos del templo de la C/ Holguín”. En Mateos, P. (ed.): El 'Foro Provincial' de Augusta Emerita: un conjunto monumental de culto imperial. Anejos de Archivo Español de Arqueología, 42. Madrid: csic, pp. 122-139.

Mélida, J. R. y Macías, M. (1929): Excavaciones de Mérida. El circo. Los columbarios. Las termas. Esculturas. Hallazgos diversos. Memoria de los trabajos practicados en 1926 y 1927. Memorias de la Junta Superior de Excavaciones y Antigüedades, 98. Madrid: Imprenta de Archivos.

Montalvo, A. M.; Gijón, M. E. y Sánchez-Palencia, F. J. (1997): "Circo romano de Mérida. Campaña de 1995”, Mérida. Excavaciones Arqueológicas 19941995. Memoria, 1, pp. 245-258.

Noguera, J. M.; Madrid, M. J. y Quiñonero, D. (2009): "Nuevas aportaciones al urbanismo de Carthago Noua: la insula I del Molinete y la red viaria de la colonia”. En Noguera, J. M. y Madrid, M. J. (eds.): Arx Hasdrubalis. La ciudad reencontrada. Arqueología en el cerro del Molinete / Cartagena. Murcia: Univ. de Murcia, pp. 68-81.

Oberhofer, K (2018): "Archäologische und stratigraphische Untersuchungen zu Haus 8”. En Teichner, F. (ed.): Mirobriga. Eine Stadt im fernen Westen des Imperium Romanum. Kleine Scriften, 62. Marburg: Vorgeschichtliches Seminar der Philipps-Univ. Marburg, pp. 128-147.

Palma, P. (2001): “Ampliación al conocimiento del trazado viario romano de Mérida. Intervención arqueológica realizada en el solar de la c/ Lope de Vega", Mérida. Excavaciones Arqueológicas 1999. Memoria, 5, pp. 225-241.

Palma, P. (2009): "Solar de la calle Viñeros, 17". En Ayerbe, R.; Barrientos, T. y Palma, F. (eds.): $E l$ Foro de Augusta Emerita. Génesis y evolución de sus

Zephyrus, LXXXVIII, julio-diciembre 2021, 135-161

Ediciones Universidad de Salamanca / @@BO 
frente a la escorrentía superficial en Augusta Emerita (Mérida) y Mirobriga (Santiago do Cacém, Portugal)

recintos monumentales. Anejos de Archivo Español de Arqueología, 53. Mérida: Csic-IAM, pp. 331-366.

Pizzo, A. (2015): "Los acueductos de Augusta Emerita: técnicas y procesos de construcción”. En Borau, L. y Borlenghi, A. (eds.): Aquae Ductus. Actualité de la recherche en France et en Espagne. Actes Colloque International (Toulouse, 2013). Supp. Aquitania, 33. Bordeaux: Fédération Aquitania, pp. 21-48.

Poenler, E. E. (2012): "The drainage system at Pompeii: mechanisms, operations and design", Journal of Roman Archaeology, 25, pp. 95-120. DOI: https://doi. org/10.1017/s104775940000115x

QuARESMA, J. C. (2012): Economia antiga a partir de um centro de consumo Lusitano. Terra sigillata e cerâmica africana de cozinha em Chãos Salgados (Mirobriga?), Estudos \& Memórias, 4. Lisboa: Centro de Arqueologia da Univ. de Lisboa.

Quaresma, J. C.; Felício, C.; Sousa, F.; Gadanho, A.; Guimarâes, R. y Da Silva, R. B. (2020): "Mirobriga (Santiago do Cacém): novos desenvolvimentos científicos, entre análises e novas escavaçōes”, Revista Portuguesa de Arqueologia, 23, pp. 121-130.

Romaní, N. (2019): Carrers $i$ serveis viaris a les ciutats romanes del conuentus Tarraconensis (segles II a. C.-VI d. C.). Forma Conventus Tarraconensis. Serie Studia Archaeologica, 2. Barcelona: IEC-UAB-ICAC.

Ruiz Bueno, M. D. (2018): Dinámicas topográficas urbanas en Hispania. El espacio intramuros entre los ss. II $y$ VII d. C. Collana Munera, 44. Bari: Edipluglia.

SánChez BARrero, P. D. (2010): Itinerarios y caminos romanos en el entorno emeritense. Ataecina, 6 . Mérida: IAM.

Sánchez Hidalgo, F. (2017): "Excavaciones en una vía periurbana altoimperial y su área funeraria; otros hallazgos coetáneos de una alberca y pozo en su entorno. Intervención arqueológica realizada en el UE-SE-11/55 de la Barriada de Plantonal de la Vera (Mérida)", Mérida. Excavaciones Arqueológicas 20062008. Memoria, 12 (2), pp. 651-675.

Sánchez Hidalgo, F. (2019): "Evolución de una domus de época altoimperial y su vía hasta la Tardoantigüedad, en un solar que se encontraba en un arrabal durante el periodo andalusí. Excavación arqueológica en el solar sito entre las calles Muza, 25 y Adriano, 19, en Mérida, promovido por el Inss", Mérida. Excavaciones Arqueológicas 2009-2011. Memoria, 13 (1), pp. 201-228.

Sánchez Hidalgo, F.; Sanabria, D. y Rosa, R. (2019): "Evolución de un área extramuros al noreste de $A u$ gusta Emerita: ámbitos funerarios, domésticos y gran edificio balneario; construcciones tardoantiguas y maqbara andalusí. Excavación arqueológica realizada en el Antiguo Cuartel Militar de Artillería 'Hernán Cortés' de Mérida", Mérida. Excavaciones Arqueológicas 2009-2011. Memoria, 13 (2), pp. 425-483.

Slane, K. W. (1988): “The Survey". En Biers, W. R. (ed.): Mirobriga. Investigations at an Iron Age and Roman site in southern Portugal by the University of Missouri-Columbia, 1981-1986. BAR Intern. Ser., 451. Oxford: Archaeopress, pp. 7-30.

Slane, K. W.; Biers, W. R.; Biers, J. C. y Soren, D. (1983): "Mirobriga: The 1983 Season", Mvse, 17, pp. 38-63.

Teichner, F. (ed.) (2018a): Mirobriga. Eine Stadt im fernen Westen des Imperium Romanum. Kleine Scriften, 62. Marburg: Vorgeschichtliches Seminar der Philipps-Univ. Marburg.

Teichner, F. (2018b): "Einleitende bemerkungen zur fundstelle”. En Teichner, F. (ed.): Mirobriga. Eine Stadt im fernen Westen des Imperium Romanum. Kleine Scriften, 62. Marburg: Vorgeschichtliches Seminar der Philipps-Univ. Marburg, pp. 9-18.

Teichner, F. (2018c): "Geophysikalische Prospektionen und stratigraphische Ausgrabungen”. En ТегсHNER, F. (ed.): Mirobriga. Eine Stadt im fernen Westen des Imperium Romanum. Kleine Scriften, 62. Marburg: Vorgeschichtliches Seminar der Philipps-Universität Marburg, pp. 35-50.

Teichner, F. (2018d): "Baugeschichtliche und stratigraphische Untersuchungen im Bereich des Forums". En Teichner, F. (ed.): Mirobriga. Eine Stadt im fernen Westen des Imperium Romanum. Kleine Scriften, 62. Marburg: Vorgeschichtliches Seminar der Philipps-Universität Marburg, pp. 156-182. 
